\title{
Toward Monitoring Short-Term Droughts Using a Novel Daily Scale, Standardized Antecedent Precipitation Evapotranspiration Index $\mathscr{D}$
}

\author{
JUN Li, ZHAOLI WANG, AND XUSHU WU \\ School of Civil Engineering and Transportation, South China University of Technology, and Guangdong Engineering \\ Technology Research Center of Safety and Greenization for Water Conservancy Project, Guangzhou, China \\ CHONG-Yu Xu \\ Department of Geosciences, University of Oslo, Oslo, Norway \\ SHENGLIAN GUO \\ State Key Laboratory of Water Resources and Hydropower Engineering Science, Wuhan University, Wuhan, China \\ XIAOHONG CHEN \\ Center for Water Resource and Environment, Sun Yat-Sen University, Guangzhou, China
}

(Manuscript received 23 December 2019, in final form 19 March 2020)

\begin{abstract}
Recent events across many regions around the world have shown that short-term droughts (i.e., daily or weekly) with sudden occurrence can lead to huge losses to a wide array of environmental and societal sectors. However, the most commonly used drought indices can only identify drought at the monthly scale. Here, we introduced a daily scale drought index, that is, the standardized antecedent precipitation evapotranspiration index (SAPEI) that utilizes precipitation and potential evapotranspiration and also considers the effect of early water balance on dry/wet conditions on the current day. The robustness of SAPEI is first assessed through comparison with two typical monthly indices [Palmer drought severity index (PDSI) and standardized precipitation evapotranspiration index (SPEI)] and soil moisture, and then applied to tracking short-term droughts during 1961-2015 for the Pearl River basin in south China. It is demonstrated that SAPEI performs as well as SPEI/self-calibrating PDSI at the monthly scale but outperforms SPEI at the weekly scale. Moreover, SAPEI is capable of revealing daily drought conditions, fairly consistent with soil moisture changes. Results also show that many of the historical short-term droughts over the Pearl River basin have multiple peaks in terms of severity, affected area, and intensity. The daily scale SAPEI provides an effective way of exploring drought initiation, development, and decay, which could be conducive for decision-makers and stakeholders to make early and timely warnings.
\end{abstract}

\section{Introduction}

Drought is thought of as one of the most complex environmental disasters, with devastating impact on agriculture, economy, water resources, and ecosystems (Maneta et al. 2009; Rhee et al. 2010; Doughty et al. 2015; $\mathrm{Yu}$ et al. 2019). At the backdrop of global warming,

Supplemental information related to this paper is available at the Journals Online website: https://doi.org/10.1175/JHM-D-190298.s1.

Corresponding author: Xushu Wu, xshwu@scut.edu.cn droughts are becoming more frequent with increasing severe consequences (Cook et al. 2014; Dai 2013). As such, much effort has been made to reveal drought characteristics and in turn help disaster mitigation.

For characterizing droughts, many indices are proposed, for examples, the standardized precipitation index (SPI) (McKee et al. 1993), the Palmer drought severity index (PDSI) (Palmer 1965), and the standardized precipitation evapotranspiration index (SPEI) (Vicente-Serrano et al. 2010a). These indices are proved robust for drought characterization, among which SPI has wide range of application due to its simple calculation and the accessible input data, that is, precipitation 
(Mishra and Singh 2010; Portela et al. 2015). However, its utilization across semiarid and arid regions is often limited because it only considers precipitation regardless of other climatic factors, for example, temperature and evapotranspiration affecting drought occurrence and development. To overcome the drawback of SPI, Vicente-Serrano et al. (2010a) proposed SPEI. Compared to SPI, this index is more flexible and reliable for drought analysis and monitoring in the context of global warming, since it simultaneously considers the effects of both precipitation and temperature (Vicente-Serrano et al. 2010a,b; Chen and Sun 2015). The PDSI is a landmark in the development of drought indices, which involves a range of factors such as precipitation, temperature, evapotranspiration, and soil moisture (Heim 2002). However, the index suffers from several deficiencies, for example, fixed temporal scale, poor performance on the frozen and snow surface, and limitation in spatial comparability (Andreadis et al. 2005; VicenteSerrano et al. 2010a). Soon after, the self-calibrating PDSI (scPDSI) was developed to overcome many of these problems (Wells et al. 2004). It is spatially comparable and reports extreme wet and dry events at frequencies expected for rare conditions. Yet the temporal time scale of scPDSI is still relatively fixed ranging from 9 to 12 months, and the values are influenced by the conditions up to 4 years in the past (Guttman 1998). Except for these, drought indices based on remote sensing data, such as the normalized difference vegetation index, anomaly vegetation index, and vegetation condition index, are developed (Rhee and Im 2017; Jiao et al. 2019), which provide new tools for drought monitoring and analyses. Although the above drought indices have their own applications, they are inevitably subjected to some main shortcomings including the fixed temporal scale that have limited their widening use.

Traditionally, drought is usually thought of as a longlasting and slow-acting climate phenomenon caused by a lack of precipitation and change of other factors over a period of months or years (Mishra and Singh 2010). However, drought is driven by multiple factors, for example, precipitation deficit, high temperature, low humidity, strong winds, and sunny skies (Otkin et al. 2013, 2014; Wu et al. 2017a). Such hydrometeorological anomalies can appear within a short period that do not formulate long-lasting droughts, but rather, short-term droughts lasting a few weeks or even days (Mo and Lettenmaier 2015, 2016; Ford et al. 2015; Otkin et al. 2015, 2016, 2018). Severe drought can suddenly occur in a region within a short period when extreme weather anomalies persist over the same region (Otkin et al. 2013). Under climate change, short-term droughts are expected to increase causing substantial damage to economic society and the environment (Quiring and Papakryiakou 2003). For example, a significant precipitation deficit along with extreme high temperature and long-lasting sunshine has caused severe droughts during May and early June in 2012 across the central United States (Mo and Lettenmaier 2015). It resulted in widespread agricultural crop failure and drastically cut down livestock population with an economic loss up to tens of billions of dollars (Mo and Lettenmaier 2015, 2016). To make early and timely warning for such short-term droughts, decision-makers and stakeholders need detailed drought information such as the start time and the tendency in the coming days rather than the drought average state for a longer period (Lu et al. 2014). Correspondingly, it is more appropriate to employ daily or weekly scale drought indices in short-term drought monitoring (Hao et al. 2017). Nevertheless, none of the aforementioned indices readily allows for identifying short-term droughts because of their relatively large temporal scales (monthly or longer); what they can tell is the overall drought situation of the period (Panu and Sharma 2002; Mishra and Singh 2010; Zhang et al. 2017). More importantly, when applied to submonthly drought characterization, the existing indices probably neglect the precipitation in the days before the period that cannot reflect real drought situation (Hoerling et al. 2014; Kam et al. 2014; PaiMazumder and Done 2016). Recently, Lu (2009) proposed the weighted average of precipitation (WAP), a daily scale index for day-to-day monitoring of drought with the aim to determine the timing and strength of short-term drought. However, the formulation of WAP only requires the precipitation variable, leaving out other important drought-related factors (e.g., evapotranspiration) that might have limitations in drought measures for wet regions ( $\mathrm{Lu}$ et al. 2014).

There is an urgent need to propose new drought indices capable of monitoring submonthly droughts, as the most commonly used indices at present have employed monthly or longer time scales failing to monitor the events effectively. In this work, we formulated a new daily-scale index for tracking short-term droughts, that is, the standardized antecedent precipitation evapotranspiration index (SAPEI), by simultaneously considering two major drought-related variables, that is, precipitation and potential evapotranspiration (PET). SAPEI also considers the effect of early water balance on dry/wet conditions on the current day. We hope to enrich indices for timely and effective short-term drought measures geared toward providing detailed information such as the initiation, development, decay, and tendency of droughts for decision-makers and stakeholders to make early and timely warnings.

\section{Sourced data and processing}

Daily meteorological data covering 1961-2017 are collected from 839 observational stations across China 


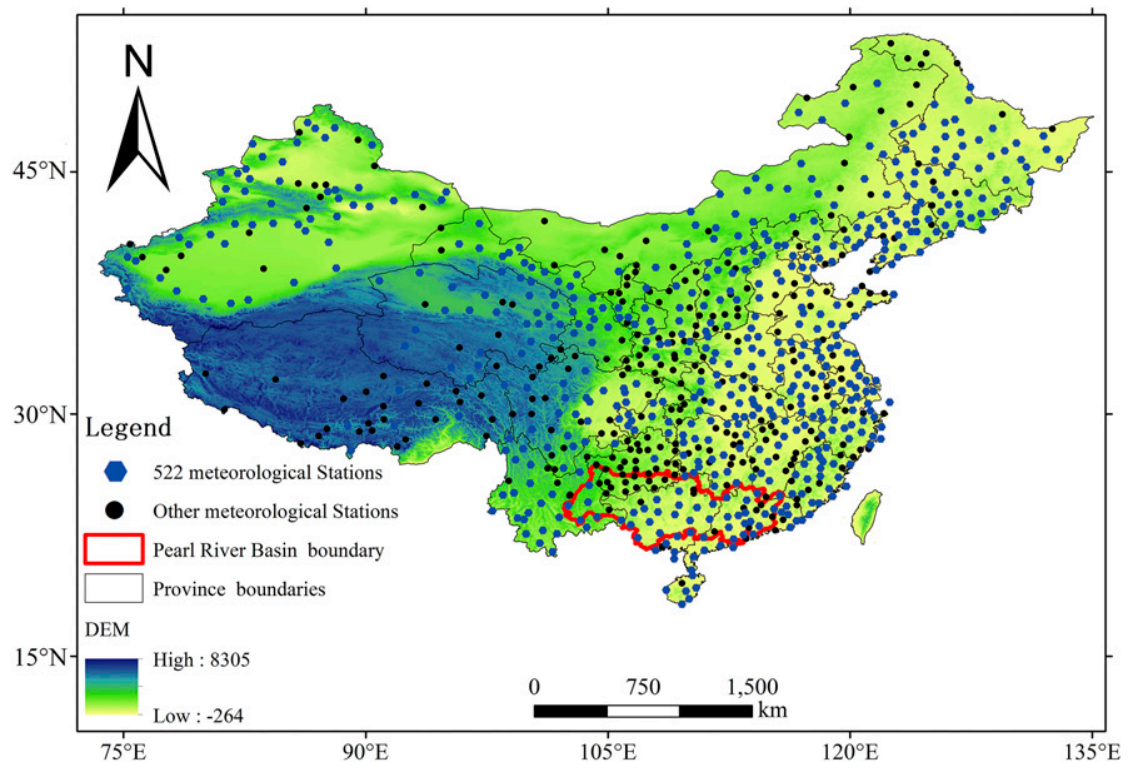

FIG. 1. Distribution of the 839 meteorological stations across mainland China used in the study.

(Fig. 1), which include precipitation, maximum air temperature, mean air temperature, minimum air temperature, relative humidity, 2-m wind speed, and sunshine duration. All of these meteorological data with strict quality controls are from the China Meteorological Administration (http://cdc.nmic.cn/home.do) and the Resources and Environmental Science Data Center, Chinese Academy of Sciences (http://www.resdc.cn/ Default.aspx). To calculate SAPEI at the grid scale, we used the kriging method to interpolate observational station data into $0.5^{\circ} \times 0.5^{\circ}$ gridded data. To evaluate the performance of SAPEI, we used two other commonly used drought indices, SPEI and scPDSI, and the monitoring abilities of the three indices are compared. Two typical drought events that respectively occurred in 2009/10 and 2011 were used in the comparison. The reports of the events can be found on the websites http://61.178.78.36:5008/category/ghxxdt and http://61.178.78.36:5008/category/ghxxdt, where drought evolutions and impacts are presented that are useful for the verification of SAPEI. SPEI is computed from the same meteorological data described above, while the scPDSI series is obtained from the Climatic Research Unit of University of East Anglia (Osborn et al. 2017), given that the calculation of scPDSI is much more complicated and time consuming than SPEI. In addition, the $0.25^{\circ}$ daily root zone $(0-100 \mathrm{~cm})$ soil moisture dataset obtained from the Community Land Model (CLM) of the Global Land Data Assimilation System (GLDAS) was also used to evaluate the rationality of SAPEI. The dataset from 1961 to 2014 was downloaded from the Goddard Earth Sciences Data and Information
Services Center (Rodell et al. 2004; Li et al. 2018). To match the spatial scale, the GLDAS soil moisture dataset was resampled to $0.5^{\circ}$ by using bilinear interpolation. The GLDAS CLM soil moisture dataset is found capable of capturing the dry and wet conditions in China (Zhang et al. 2008; Chen et al. 2013; Bi et al. 2016; Feng et al. 2016).

We also applied SAPEI for short-term drought tracking over the Pearl River basin (Fig. 1). This basin is the second largest drainage basin in China controlled by a humid climate, where short-term droughts are more likely to occur than the long-term ones (Wu et al. 2018; Gao et al. 2019). To verify the drought events identified by SAPEI, we sought to extract drought events through soil moisture given that droughts are usually accompanied by low soil water content, and compared the events distinguished by SAPEI and the soil moisture data. However, regional in situ soil moisture data are not available for such a large basin from 1961 to 2017; as an alternative, the soil moisture data were calculated from a well-known hydrological model, that is, the Variable Infiltration Capacity (VIC) model that includes three soil layers (Lohmann et al. 1998; MiguezMacho et al. 2008; Niu et al. 2015; Yan et al. 2015). Since the development of the VIC model (Liang et al. 1994), it has been widely used to simulate soil moisture and streamflow, and these studies have demonstrated that the outputs of soil moisture from VIC are reliable and reasonable (Liang et al. 1996; Nijssen et al. 2001; Hamlet et al. 2007; Ford and Quiring 2013; Xia et al. 2014). Moreover, the VIC model has been successfully applied in the Pearl River basin for soil moisture and streamflow simulations (Niu et al. 2015; Niu and Chen 2016). 

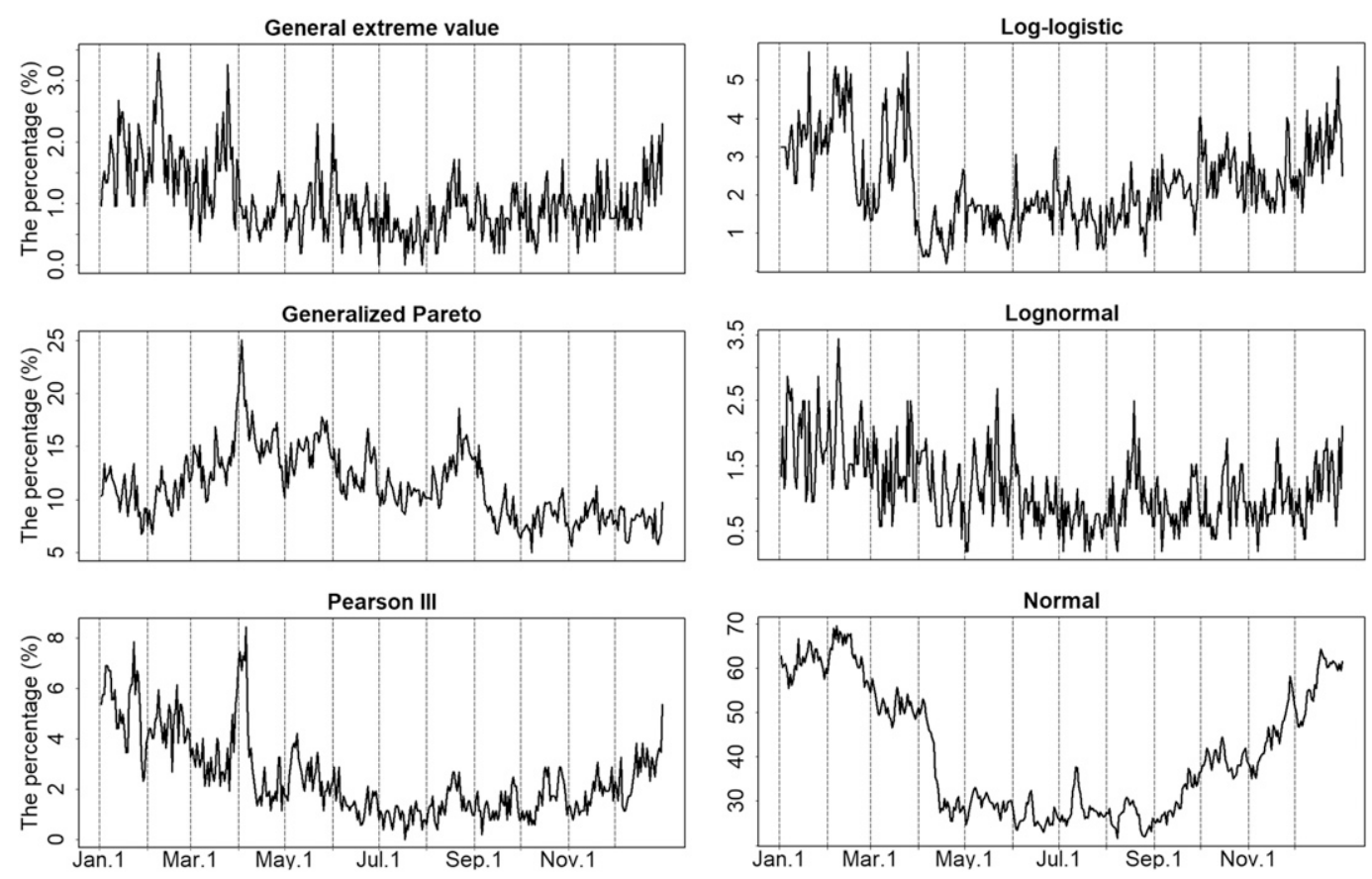

FIG. 2. Percentages of daily time series of $D$ that cannot be fitted by the six probability distributions using the Kolmogorov-Smirnov test.

Compared with observed data, the soil moisture data from the VIC model are somewhat imperfect, but the soil moisture calculated from the model is capable of capturing the variation of dry and wet conditions over the basin (Niu et al. 2015; Niu and Chen 2016; Wang et al. 2018). Therefore, a comparison between SAPEI and VIC-based soil moisture is acceptable, and we used VIC-based together with GLDAS soil moisture to indirectly verify drought events distinguished by SAPEI, and the VIC-based PET was used to calculate the SAPEI in the Pearl River basin.

The VIC model is verified through comparison between the simulated stream flows and the observations. Following the previous literatures (Zhou et al. 2016; Mizukami et al. 2019), the metrics of Nash-Sutcliffe efficiency (NSE), relative error (bias), and determination coefficient $\left(R^{2}\right)$ for evaluation of the accuracy of the model were used. A significant coincidence rate with $p<0.05$ is detected in both the calibration and validation periods, demonstrating that the VIC model is adaptable and rational. More details on the calibration and validation of the VIC model can be found in the study of Li et al. (2020a).

\section{Methodology}

\section{a. Rationale of SAPEI}

SAPEI requires precipitation and PET as the inputs; it is simple to calculate and uses the daily accumulative differences between precipitation and PET representing a simplified climatic water balance (Thornthwaite 1948). The calculation procedure is described below.

The first step is to estimate PET. Accurate calculation of PET is rather difficult due to the requirement of numerous climate variables including surface temperature, air humidity, radiation and so on (Allen et al. 1998; Vicente-Serrano et al. 2010a). There are several prevailing methods to estimate PET, for example, the PenmanMonteith method (Allen et al. 1998) and Thornthwaite equation (Thornthwaite 1948). The Thornthwaite equation only involves the mean daily temperature and latitude without consideration of changes in solar and infrared radiation, humidity, or wind speed (Trenberth et al. 2014). Additionally, it cannot reveal spatiotemporal evolution of evapotranspiration well (Chen et al. 2005). Compared to the Thornthwaite equation, the Penman-Monteith method is more physically based which considers energy availability, humidity, and wind speed. Therefore, we used the Penman-Monteith method to estimate PET. Details of the Penman-Monteith method can be found in Allen et al. (1998).

Afterward, the daily difference between precipitation and PET is calculated to reveal water surplus or deficit (precipitation minus PET). To reflect dry and wet conditions of the day, the antecedent water surplus or deficit $D$ is calculated through the following equations: 

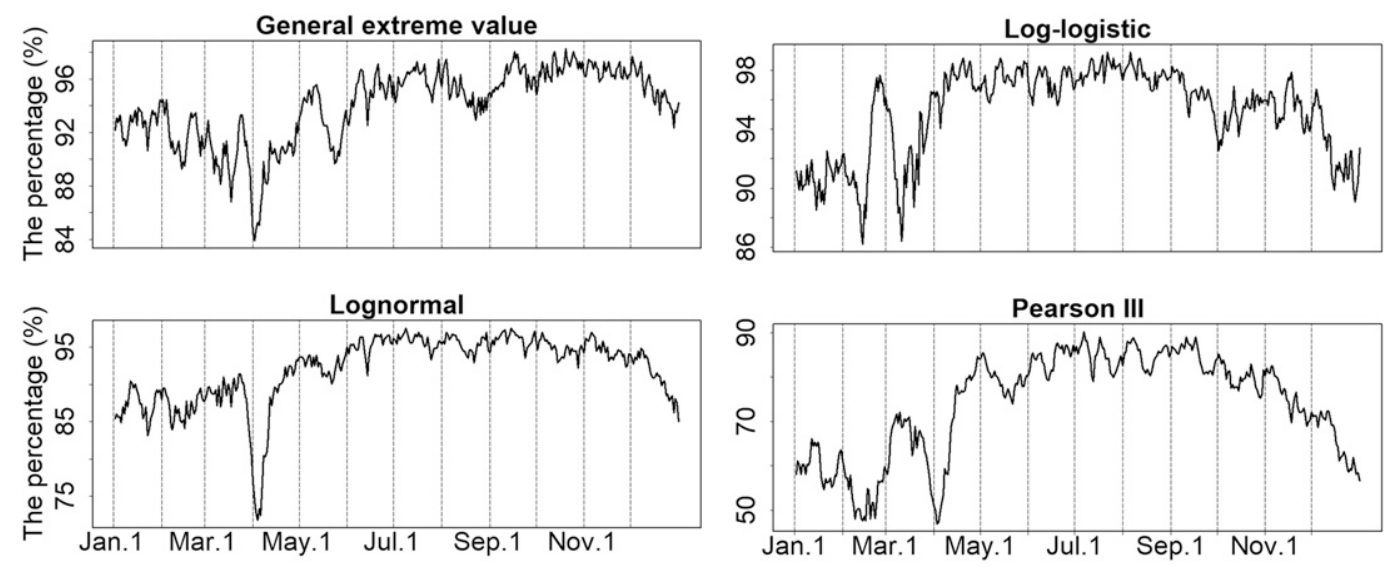

FIG. 3. Percentages of normally distributed daily SAPEI series calculated using the four probability distributions.

$$
\begin{aligned}
D & =\sum_{n=0}^{N} a^{n}(p-\mathrm{PET})_{n}, \\
a^{N} & =c,
\end{aligned}
$$

where $N$ is the number of previous days, $a$ is the decay constant, and $c$ is the contribution fraction of the last day precipitation. In the current study, $a=0.98$ and $c=13 \%$ resulting in $N=100$ (see section 4 a).

A probability distribution is used to fit the $D$ series. Several probability distributions, including the general extreme value, log-logistic, lognormal, Pearson III, generalized Pareto, and normal distributions, have been broadly used to standardize hydrometeorological variables (Stagge et al. 2015; Wu et al. 2016). These distributions are considered reliable tools to calculate comparable drought indices (Vicente-Serrano et al. 2018). Given that different probability distributions may cause distinct differences in drought indices (Stagge et al. 2015), to select the most suitable distribution, we calculated six different SAPEI datasets, each of which is based on one of the above probability distributions. The probabsility

weighted moments are used for parameterizations of the distributions. The cumulative probability of $D$ is obtained when daily $D$ series is fitted to a probability distribution. The classical approximation of Abramowitz and Stegun (1965) is finally used to obtain SAPEI, similar to the calculation procedure of SPEI. In some cases, it is impossible to get SAPEI according to some of the six distributions because the parameters are not necessarily suitable. To assess the performance and robustness of the six probability distributions, the Kolmogorov-Smirnov test is applied to calculating the percentages of daily $D$ series that cannot be fitted by these distributions $(0.05$ significance level), and the distributions with high rejection percentages are not considered. For the remaining distributions, the Shapiro-Wilk test is employed to test if each SAPEI dataset is normally distributed. The benefit of the Shapiro-Wilk test is that it is independent of the candidate distribution and has well-reviewed and sensitive critical values (Stagge et al. 2015; Vicente-Serrano et al. 2018). A rejection rate with $p<0.05$ is applied to distinguishing the normally distributed SAPEI (VicenteSerrano et al. 2018).
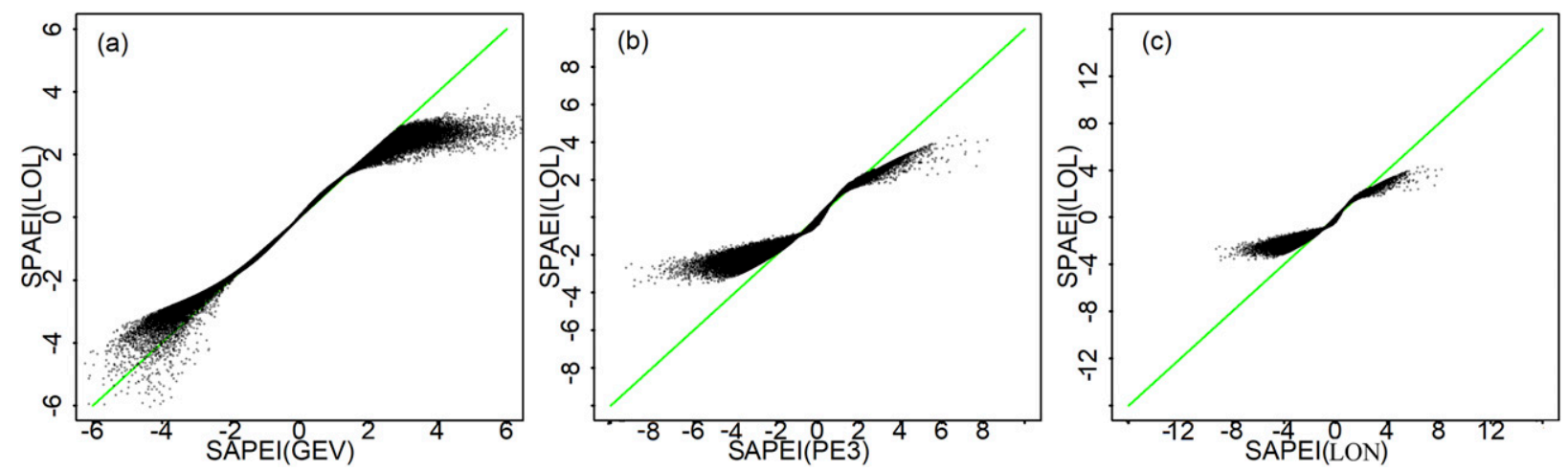

FIG. 4. Relationships between SAPEIs obtained from (a) the general extreme value (GEV) and the log-logistic (LOL), (b) the Pearson III (PE3) and LOL, and (c) lognormal (LON) and LOL computed from the 522 stations across China. 
TABLE 1. Drought categories of SAPEI.

\begin{tabular}{clc}
\hline \hline SAPEI & Drought category & Probability (\%) \\
\hline$>-0.50$ & Normal & 69 \\
$(-1.00,-0.50]$ & Mild drought & 15 \\
$(-1.50,-1.00]$ & Moderate drought & 10 \\
$(-2.00,-1.50]$ & Severe drought & 5 \\
$\leq-2.00$ & Extreme drought & 1 \\
\hline
\end{tabular}

We used the $D$ series calculated from 522 observational stations across China (Fig. 1), given that the temporal coverage of all climate variables recorded exceeds $99.7 \%$, and these stations are almost evenly distributed in different China's climatic zones. The missing data are interpolated using the arithmetic average of the neighboring days. Figure 2 shows the percentages of the daily series that cannot be fitted by the six probability distributions. It is indicated that the generalized Pareto and normal distributions do not fit SAPEI well and hence are not considered. Among the remaining four distributions, the general extreme value and lognormal distributions show better performances. Figure 3 further illustrates the percentages of the normally distributed daily SAPEI for the four remaining distributions. The general extreme value, loglogistic, and lognormal distributions have better performances compared with the Pearson III distribution in terms of the rejection percentage, and the log-logistic distribution has lowest percentage indicating the best performance. The Pearson III distribution has relatively high rejection percentage during January-March. Note that the main limitation of the Shapiro-Wilk test is that the most relevant values for a drought index are in the tail of a distribution (Vicente-Serrano and Beguería 2016; VicenteSerrano et al. 2018). To select the best distribution, the SAPEIs obtained by the four remaining distributions from the 522 stations are compared in Fig. 4. The SAPEI calculated from the general extreme value, Pearson III, and lognormal distributions have more high values in both tails than those obtained from the log-logistic distribution, and this is particularly true for the lognormal distribution, suggesting that the log-logistic distribution is more suitable for SAPEI. Moreover, previous researches have demonstrated that the log-logistic distribution is suitable for standardizing drought indices, for example, SPEI (Vicente-Serrano et al. 2010a,b, 2018). Therefore, we chose the log-logistic distribution to compute SAPEI. Accordingly, Table 1 categorizes five grades of SAPEI representing from normal to extreme droughts.

\section{b. Short-term drought identification and characteristics}

In previous studies on monthly drought indices, methods that are used to identify drought events include the threshold level method, run theory, and empirical orthogonal functions (Xu et al. 2015). However, the common drawback of these methods is the destruction or discard of much spatiotemporal drought information because they descend drought event dimensions. Consequently, these methods fail to capture real drought structures in space-time dimensions (Xu et al. 2015; LloydHughes 2012). To effectively identify drought events, the three-dimensional clustering algorithm has been proposed to fulfill the complete spatiotemporal representation of drought (Lloyd-Hughes 2012). Here we used this method to identify short-term droughts based on SAPEI, and the details are stated below.

Step 1: Drought patch identification is conducted in each time step (daily scale) during the growing season (April-September), as rapid development of climate anomalies outside the growing season has less impact on society and the environment (Christian et al. 2019). The first grid with SAPEI $<-1$ is defined as the starting point and the adjacent grids under drought conditions are also picked out and merged into the current drought patch. The adjacent grid searching process is repeated until no adjacent grids are under drought conditions. The first drought patch in the current time step is achieved and the small and discontinuous patches are omitted.

Step 2: A threshold of drought affected area is determined to filter out drought patches with relatively small affected areas, considering that the durations of such drought patches could be long due to tenuous spatial connectivity (Sheffield et al. 2009). It is suggested that the appropriate threshold comes out to be $1.6 \%$ of the region of interest (Xu et al. 2015). Hence, we followed the suggestion and picked out each drought patch whose affected area accounts for no less than $1.6 \%$ of the study region.

Step 3: The overlap area between two drought patches is calculated for two consecutive days. To eliminate ambiguous drought events, a threshold of overlapping area of $1.6 \%$ of the study region is specified (HerreraEstrada et al. 2017), and the two drought patches belong to a same event if their overlapping area is larger than this threshold, otherwise are considered as two independent events.

Step 4: Given that hydrometeorological factors anomalies generally persist for several weeks (Otkin et al. 2016, 2018), the drought events lasting for $2-4$ weeks only are selected, and drought events are characterized by the following variables.

1) Drought event duration (DED), referred to as the time interval between the start and ending times of the drought event. 

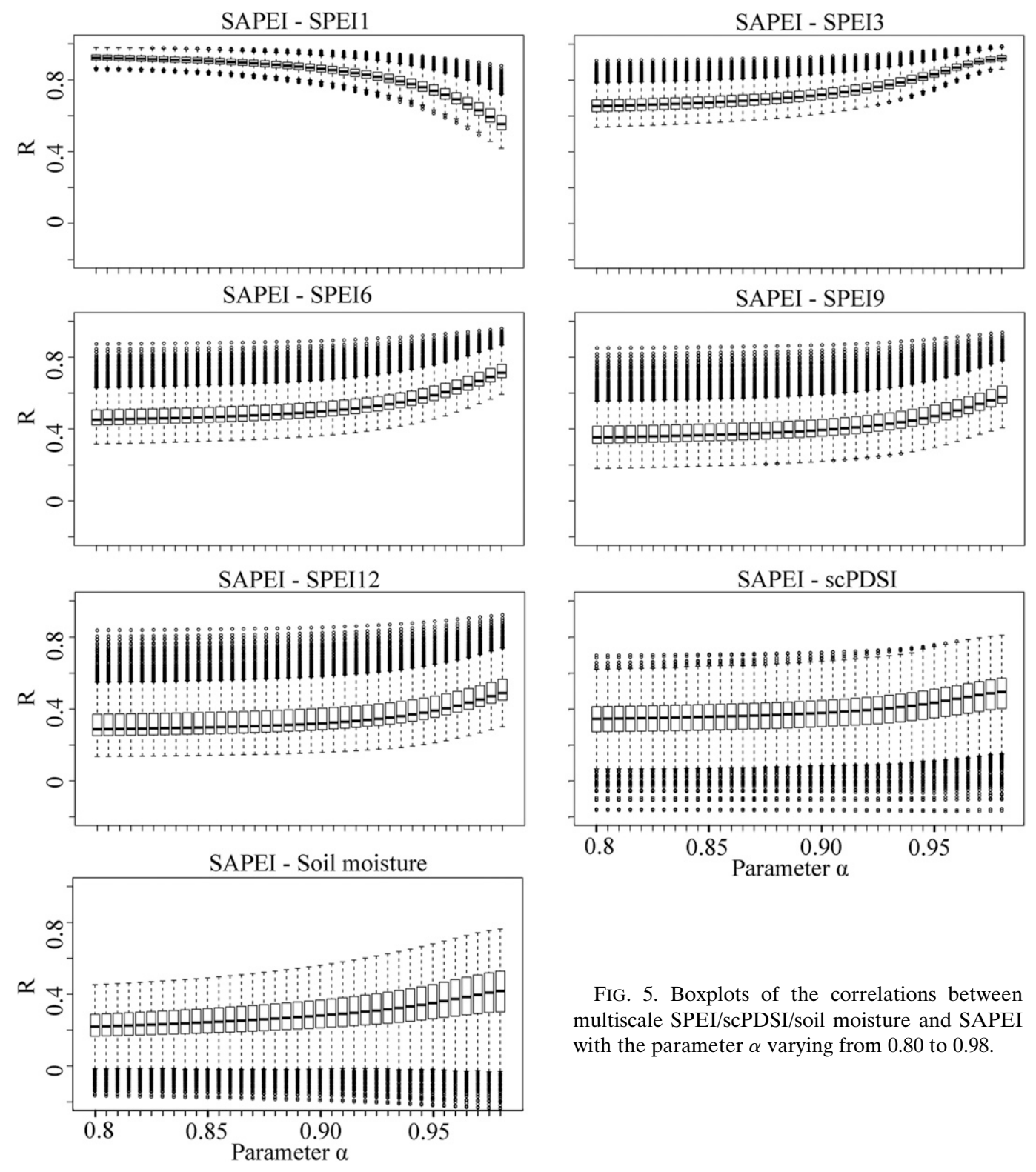

2) Drought event severity (DES), formulated as

$$
\begin{aligned}
\operatorname{DES}_{n} & =\sum_{i} \sum_{j} \sum_{k} s(i, j, k) \\
s(i, j, k) & =\operatorname{SAPEI}(i, j, k) \times \operatorname{area}(i, j, k) \times 1 \text { day }
\end{aligned}
$$

where $\mathrm{DES}_{n}$ is the severity of the $n$th drought event ( $\mathrm{km}^{2}$ day), $i$ and $j$ indicate the grid location, and $k$ is the drought event duration (i.e., DED). Also, $s(i, j, k)$ is the daily drought severity of a grid during the $n$th drought event; area $(i, j, k)$ is the area of the grid cell $(i, j)$.

3) Drought event intensity (DEI), defined as drought severity divided by drought duration and area.

4) Drought event area (DEA), defined as the total area affected by a drought event which is the projected area on the surface of latitude-longitude.

In addition, we calculated the daily severity (DS), intensity (DI), and area (DA) during a drought event to further capture drought characteristics. DI is defined as the average SAPEI of all grids at each time step during a drought event, while DA is the total area of these grids; DS is defined as the cumulated SAPEI value and drought affected area. 
(a)
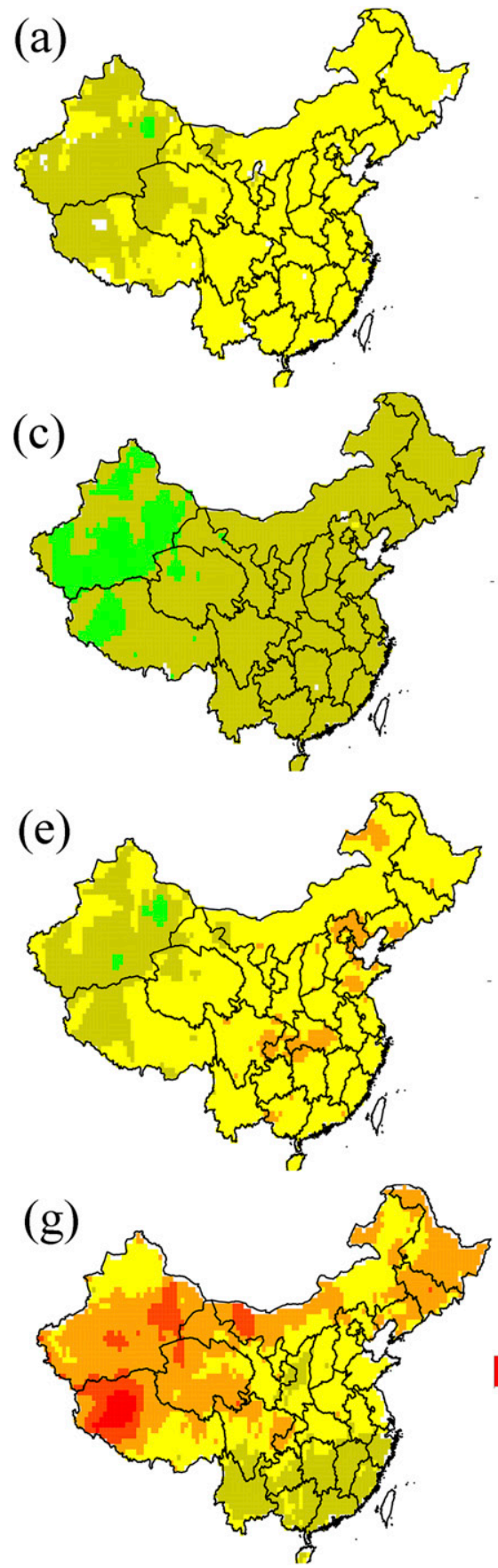
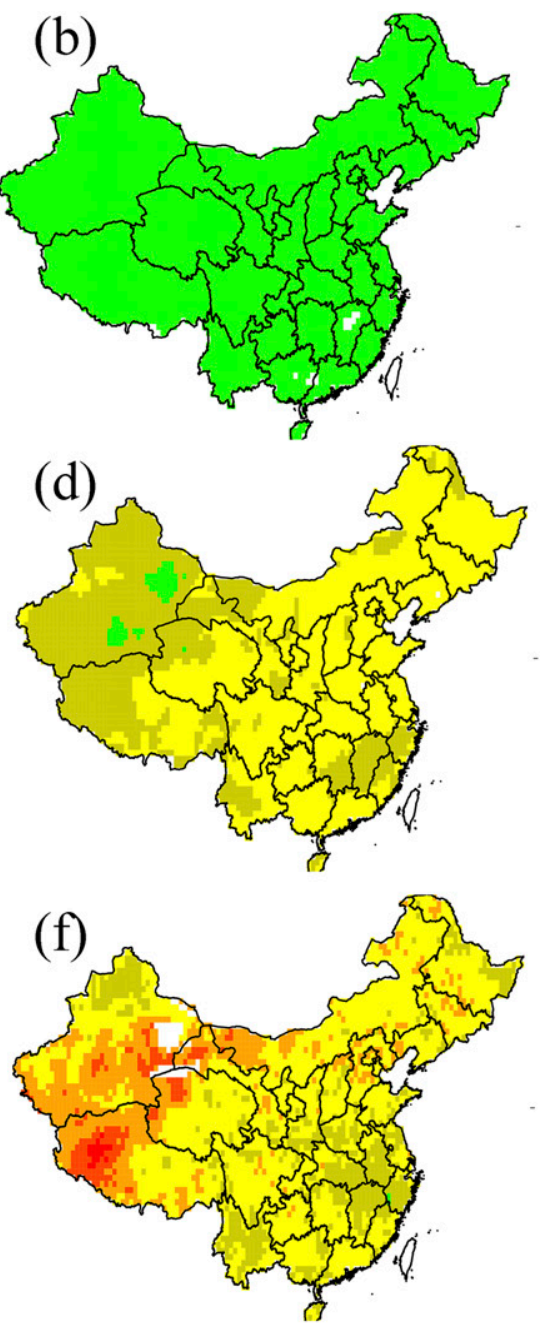

FIG. 6. Spatial patterns of correlations between monthly mean SAPEI and (a) 1-month SPEI, (b) 3-month SPEI, (c) 6-month SPEI, (d) 9-month SPEI, (e) 12-month SPEI, (f) scPDSI, and (g) between daily SAPEI and soil moisture anomalies. The monthly mean SAPEI is computed by averaging the daily values in each month.

\section{Results and discussion}

\section{a. Evaluation of SAPEI}

The parameter $\alpha$ indicates the difference between precipitation and PET for both the current and previous days contributing to dry and wet conditions of the current day, whose value generally ranges from 0.80 to 0.98 (Heggen 2001). Therefore, SAPEI is calculated with $\alpha$ varying from 0.8 to 0.98 in the current study. More specifically, the monthly means of SAPEI are obtained 

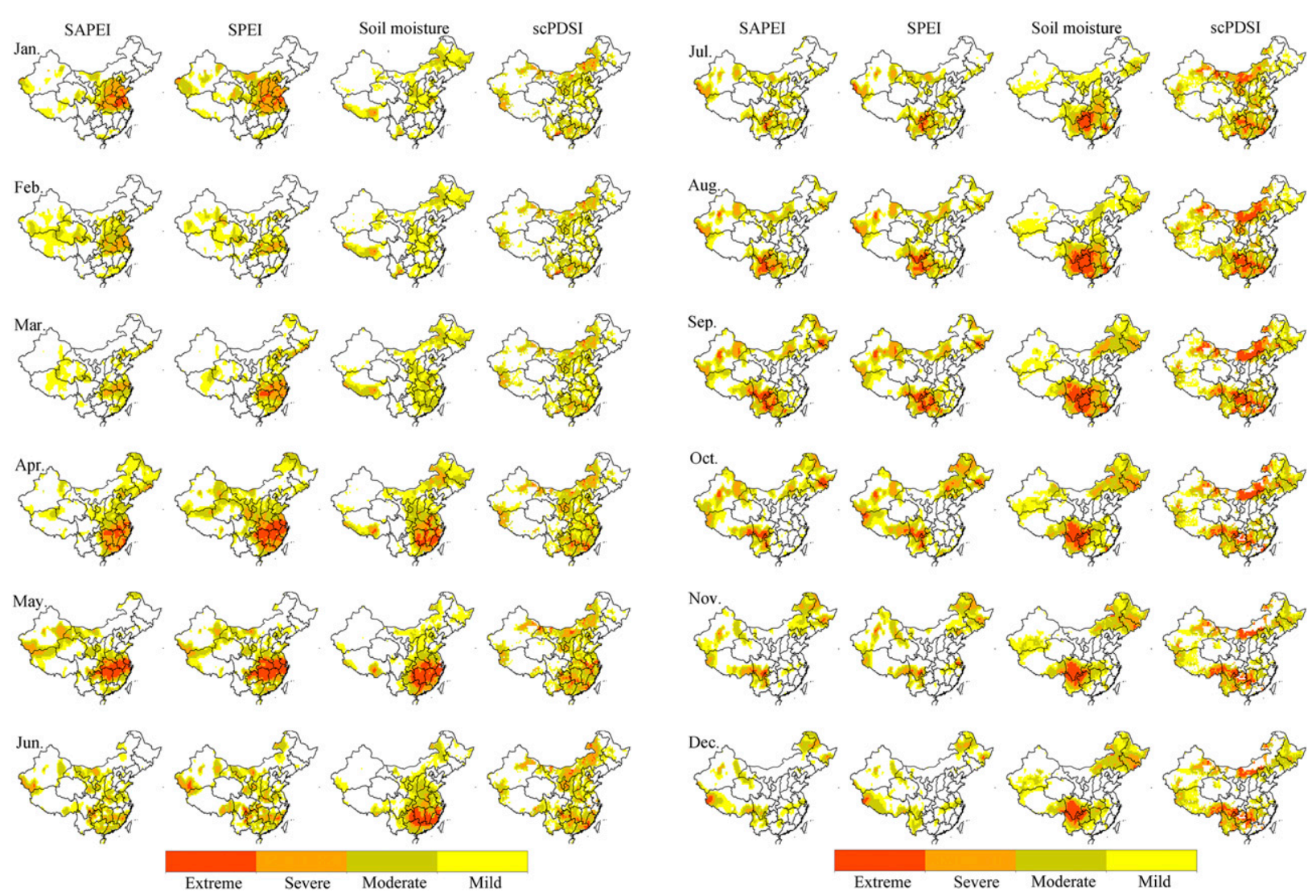

FIG. 7. Monthly evolutions of the 2011 drought event across China using SAPEI, SPEI, scPDSI, and soil moisture anomalies. The monthly SAPEI and soil moisture anomalies were computed by averaging the daily values in each month.

based on the range of $\alpha$, and are compared with two well-known drought indices, that is, SPEI and scPDSI. Figure 5 shows the correlation coefficients between SPEI/scPDSI/soil moisture and SAPEI for all grids from 1961 to 2017. Obviously, when $\alpha$ gets larger, the correlations increase gradually, indicating SAPEI with larger $\alpha$ is closer to 3-12-month SPEI, scPDSI, and soil moisture. When $\alpha=0.98$, the correlation coefficients between SPEI at the 3- and 6-month scales and SAPEI are larger than $0.6(p<0.01)$ for all grids, and the correlation coefficient between scPDSI/soil moisture and SAPEI in a majority of grids is larger than $0.4(p<0.01)$. More importantly, SAPEI tends to show smaller fluctuations with the increase of $\alpha$. Generally, $\alpha$ is determined empirically, given that it is difficult to select the most suitable value according to daily dryness ( $\mathrm{Lu} 2009$; Lu et al. 2014). In light of these we chose $\alpha=0.98$ in the study.

When a new index is proposed, rigorous testing is required with respect to its rationality and applicability before it is applied in drought monitoring (Stagge et al. 2015). Figure 6 shows the spatial distributions of the correlations between monthly means of SAPEI and
SPEI/scPDSI during 1961-2017 across China. The 3-, 6-, 9-, and 12-month SPEIs all show strong agreements with SAPEI, and the agreement between 3-and 6-month SPEI and SAPEI is the strongest for China as a whole. In the entire China, SAPEI and SPEI at the time scales of 3 and 6 months generally correlate closely, with correlation coefficients higher than $0.6(p<0.01)$ and most of places even higher than 0.8 for 6 -month SPEI. By comparison, the correlation between 1- and 9-month SPEI and SAPEI is relatively low in west China. SAPEI and scPDSI are also correlated with correlation coefficients higher than $0.4(p<0.01)$ for a majority of China, although the correlation in some part of west China is relatively lower. For SAPEI and soil moisture, a good correlation $(p<0.01)$ between SAPEI and soil moisture is detected in most of China, while the relatively weak correlation is found in most parts of west China.

Further, two typical historical severe droughts that occurred in China are taken as case studies to evaluate the performance of SAPEI. One is a well-known largescale drought event striking almost the entire country with serious consequences in the year 2011 ( $\mathrm{Li}$ et al. 2020b) and the other is a regional drought event but with 


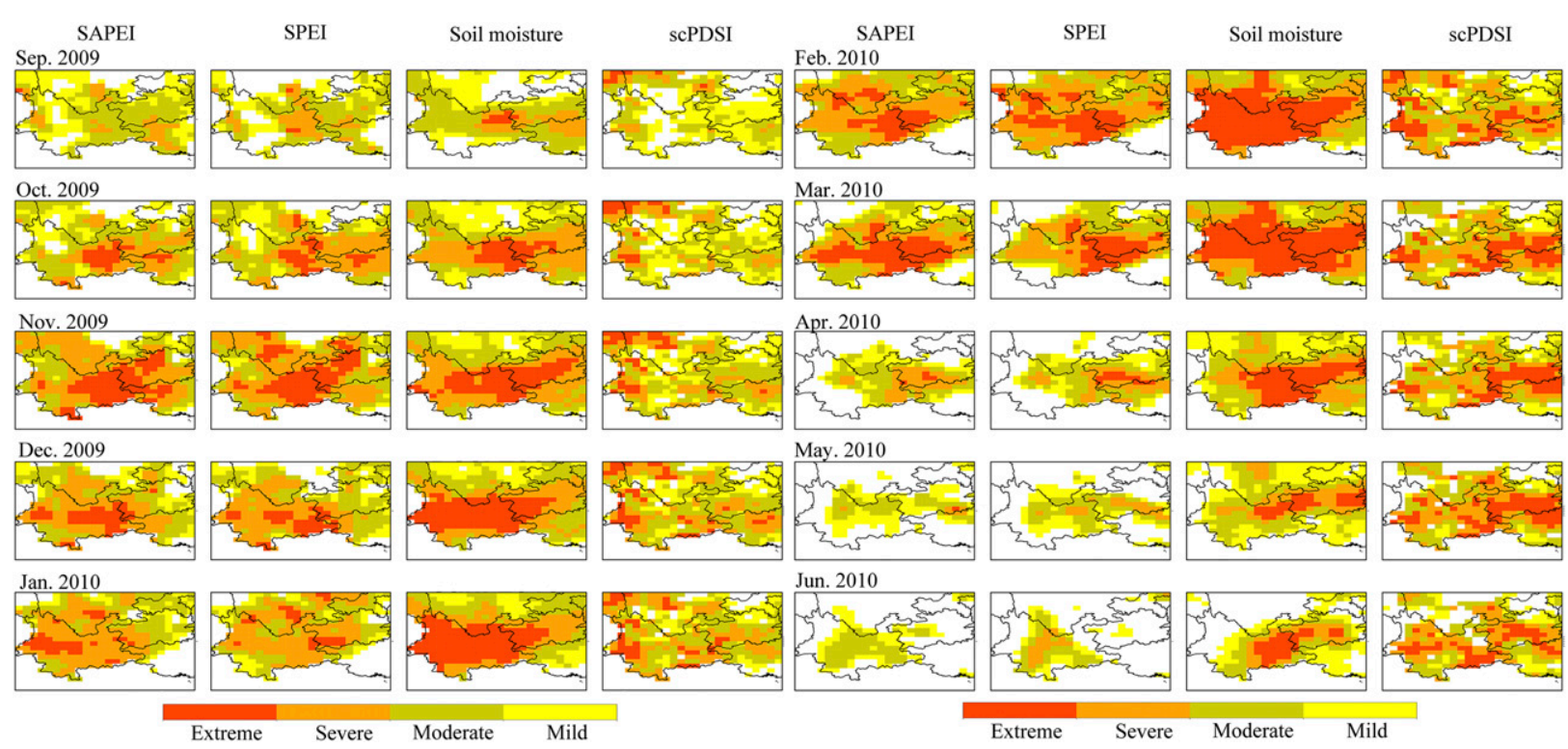

FIG. 8. Monthly evolutions of the 2009/10 drought event across southwest China monitored by SAPEI, scPDSI, 3-month SPEI, and soil moisture anomalies. The monthly SAPEI and soil moisture anomalies were computed by averaging the daily values in each month.

huge adverse impacts on society and the environment spanning the second half of 2009 and the first half of 2010 (Wang et al. 2015). According to the Meteorological Disaster Yearbook, the 2011 drought originated from north China at the beginning of the year, while in the spring and summer it spread toward south China where severe lack of rainfall occurred that year making the drought reaches the 50-yr return level. Afterward, the drought propagated into southwest China in the autumn. It forced 4.2 million people and 3.2 million livestock to face drinking water shortages and caused 3.7 million hectares of crop failure. Moreover, the prolonged drought led to more than 1300 dried-up lakes in the Yangtze River basin. In comparison, the 2009/10 drought initiated in the fall of 2009 and lasted until the June of 2010, resulting in more than 16 million people and 11 million livestock suffering from severe water shortages and a direct economic loss of approximately 2.7 billion dollars (Long et al. 2014; Wang et al. 2015).

As illustrated above, among the multiscale SPEIs, the 3-month SPEI shows strongest relationship with SAPEI. Concurrently, SPEI at the 3-month scale is much more commonly used than at other time scales in the research community (Vicente-Serrano et al. 2010a,b; Chen and Sun 2015). Therefore, the performances of SAPEI are compared with those of 3-month SPEI hereafter. Figure 7 displays the monthly changes in the 2011 drought monitored by the SAPEI, 3-month SPEI, soil

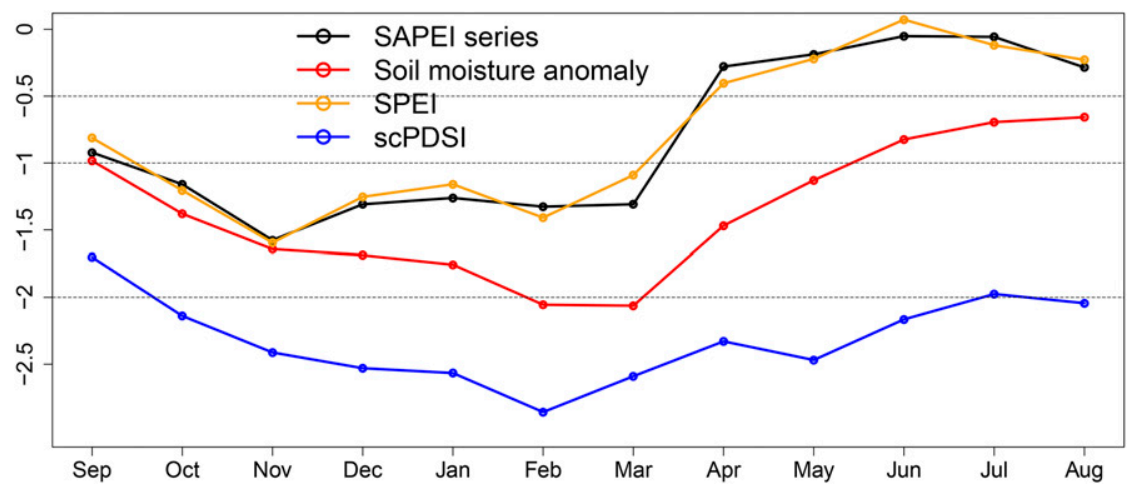

FIG. 9. Monthly SAPEI, SPEI, scPDSI, and soil moisture series during the 2009/10 drought event over southwest China. These series are spatially averaged merged series. The monthly SAPEI and soil moisture anomalies were computed through averaging the daily values in each month. 


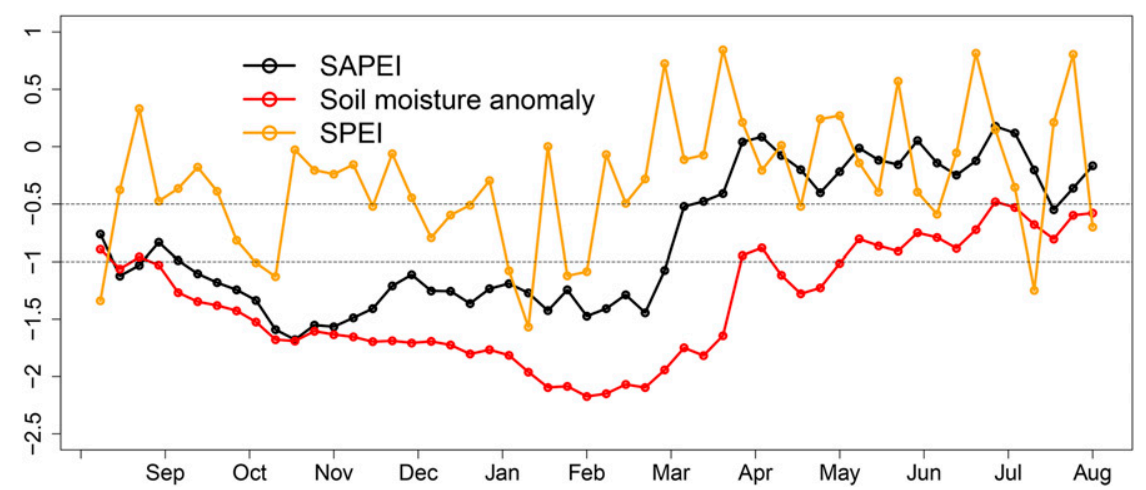

FIG. 10. Weekly SAPEI, SPEI, and soil moisture anomalies during the 2009/10 drought event over southwest China. These series are spatially averaged merged series. The weekly SAPEI and soil moisture anomalies were computed through averaging the daily values in each week.

moisture, and scPDSI. The drought pattern monitored by SAPEI generally shows a favorable similarity with those by 3-month SPEI, scPDSI, and soil moisture, suggesting that SAPEI is capable of capturing drought evolution. More specifically, the drought began in north China in January, while in March it propagated southward to the mid and lower reaches of the Yangtze River with increasing intensity. In April, however, it became much more serious, and extended from the Yangtze River basin to the entire South China. In August, the drought moved westward and reached the edge of southwestern China. Severe drought persisted in the region during September and October, but it gradually faded away in November and December. Overall, the monthly changes in the major drought affected area across China based on SAPEI are consistent with the news reports. In addition, we found that the results monitored by the new drought index are in accord with the findings of Lu et al. (2014) and Liu et al. (2017). For the 2009/10 drought event, as Fig. 8 shows, SAPEI also shows favorable agreement with the 3-month SPEI,
scPDSI, and soil moisture; the drought affected areas especially those controlled by extreme drought conditions monitored by SAPEI, scPDSI, 3-month SPEI, and soil moisture are similar, and the changes in drought intensity are basically synchronized. More specifically, the drought initiated in September 2009, and reached the peak in December in terms of intensity and affected area. It was somewhat alleviated in January and February of 2010 but became enhanced again and reached another peak in the next two months. In May, the drought started to diminish and disappeared in the early summer. With all of this in mind, it can be concluded that SAPEI is reliable and robust for capturing drought events.

Subsequently, we revealed how well SAPEI can monitor daily scale droughts and selected the aforementioned 2009/10 drought event in southwest China as the case. We first presented the monthly temporal variations of SAPEI, SPEI, scPDSI, and soil moisture anomalies (Fig. 9), and as expected these series show similar changes. But when looking into the weekly changes, it is

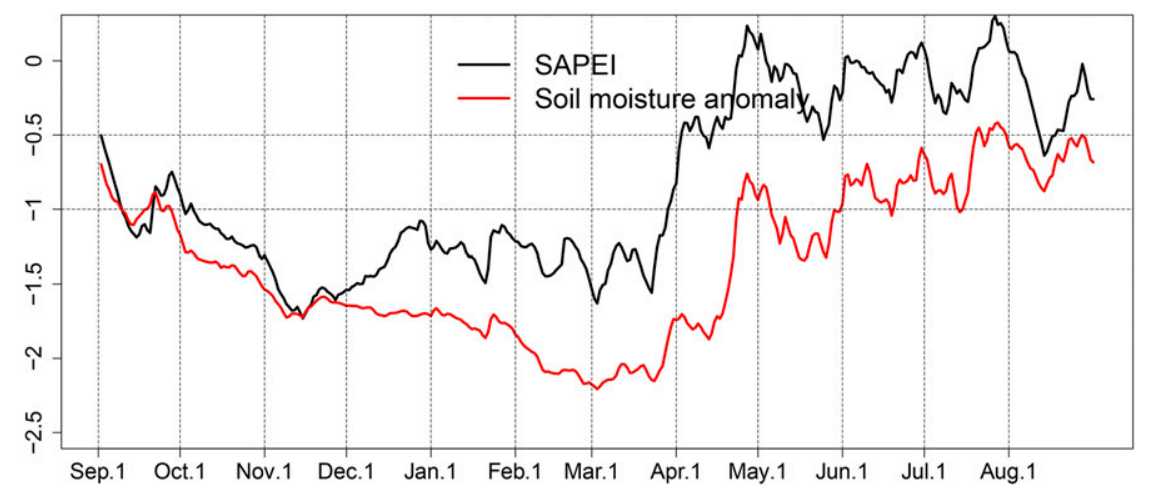

FIG. 11. Daily SAPEI and soil moisture series during the 2009/10 drought event over the southwest China. The two series are spatially averaged merged series. 
(a) Sep 1 - Oct 7

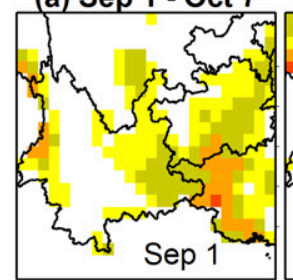

(c) Nov 4 - Nov 13

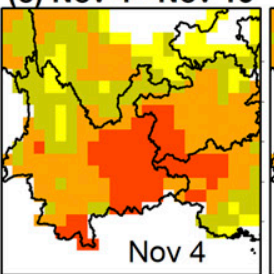

(e) Dec 18 - Dec 28

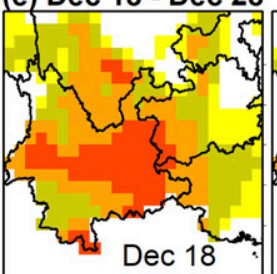

(g) Jan 6 - Feb 16

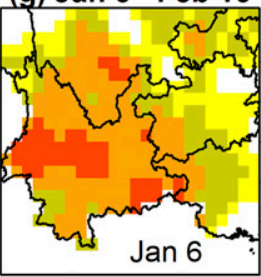

(i) Feb 26 - May 18

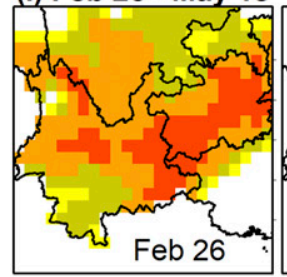

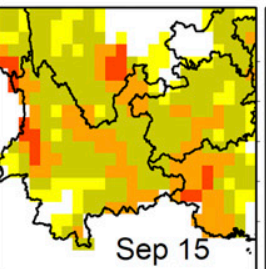
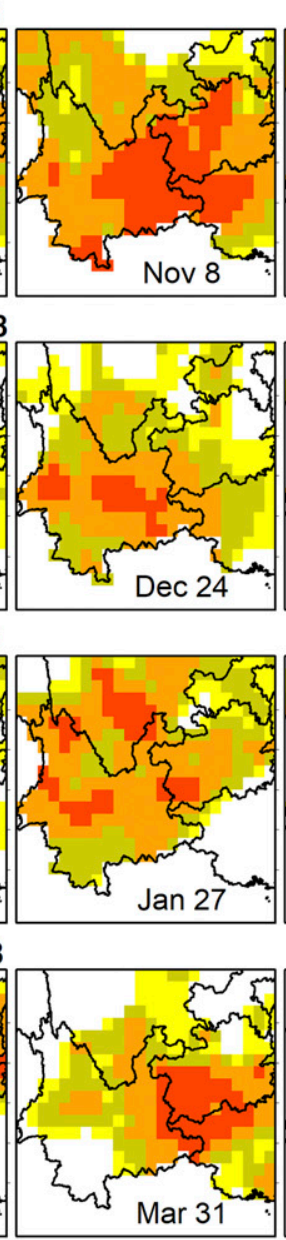

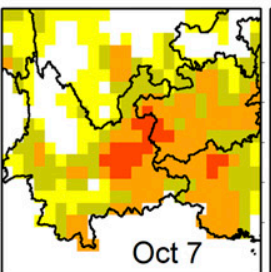

(b) Oct $8-\operatorname{Nov} 3$
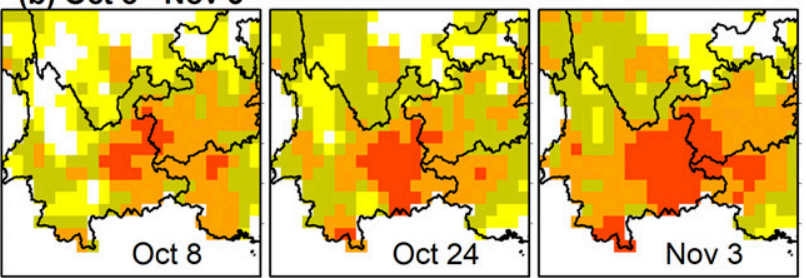

(d) Nov 14 - Dec 17
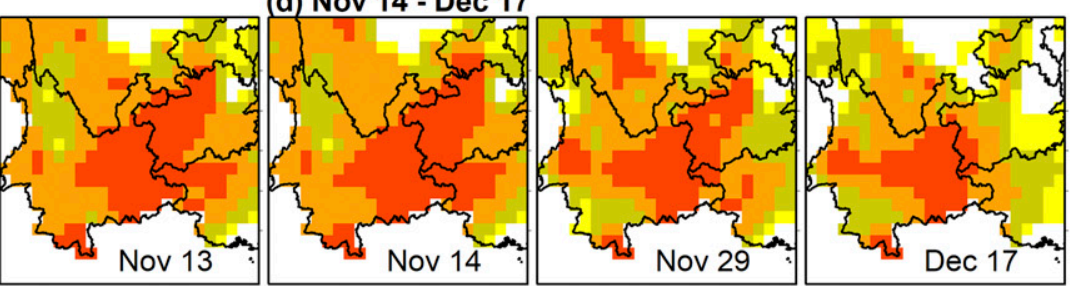

(f) Dec 29 - Jan 5
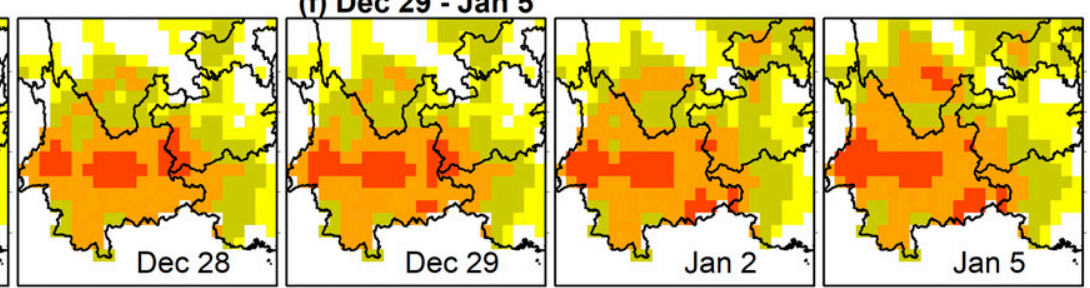

(h) Feb 17 - Feb 25
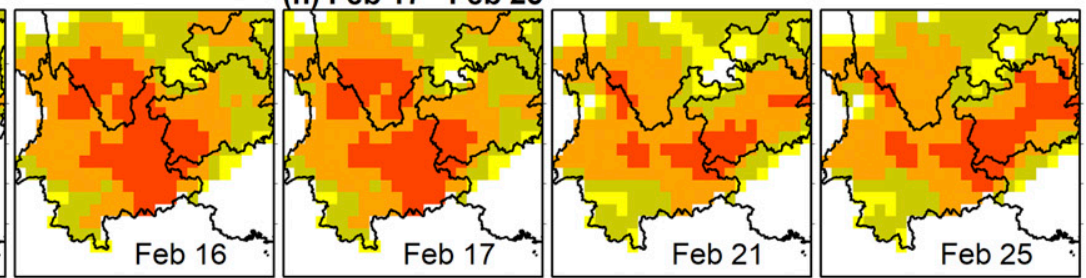

(i) May 19 - Jun 30
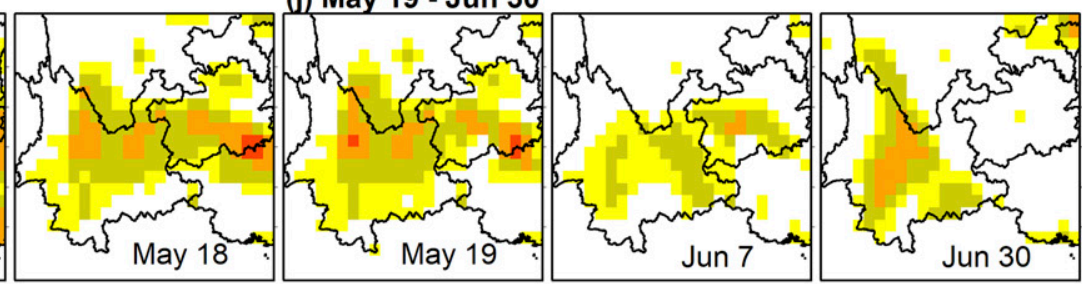

Extreme Severe Moderate Mild

FIG. 12. Daily evolutions of the 2009/10 drought event over the southwest China monitored by SAPEI.

found that the weekly SPEI shows large fluctuations, dividing this prolonged and severe drought into several short-term droughts (Fig. 10). The weekly SPEI maps indicate that drought did not even occur in southwest China in some weeks during this period (Fig. S1 in the online supplemental material), which is totally different from the actual situation. In contrast, weekly SAPEI and soil moisture are generally consistent and both of them can well capture drought conditions. All these demonstrate that SAPEI has the advantage over SPEI in terms of weekly drought monitoring. Moreover, the temporal changes in daily SAPEI and soil moisture, as illustrated in Fig. 11, indicate that daily SAEPI during this period is generally consistent with soil moisture, and both infer that drought started in September 2009, and became rather severe during February and March in 2010; after that period, the drought gradually alleviated. Figure 12 maps the spatial development of the drought event at the daily scale, which divides the entire drought period into 10 stages reflecting the initiation, maintenance, and 
relief of the event. In the first stage, that is, during 1 September and 7 October 2009, the drought started to appear in the region. Drought then spread throughout the southern part of southwest China and dry conditions became worse in the following stage (from 8 October to 3 November). In the third stage during 4-13 November, drought extended to almost the whole region, and severe drought conditions lasted from 14 November to 17 December with relatively high intensity. Afterward, drought was alleviated in the northern part of the region from 18 to 28 December. However, it intensified again from 29 December to 5 January 2010, overwhelming almost the whole region. In the following two stages (during 6 January and 25 February), there was a tendency toward alleviating drought conditions. Yet the drought developed again and extreme drought conditions were seen in the central part of the region from 26 February to 18 May. From 19 May onward, the drought diminished over time in most parts of southwest China by the end of June. These monitored daily scale changes in the 2009/10 drought are fairly in accord with the news reports.

The above demonstrates that SAPEI not only can monitor monthly characteristics of droughts, but also has the potential to track droughts at the daily and weekly scales which SPEI can barely do (Fig. S1). Though the raw data, including precipitation and potential evapotranspiration, and standardized method of SAPEI are similar with those of SPEI, the rationale of the index is different from SPEI. The calculation of SAPEI is based on a daily scale and it considers the water surplus or deficit of the day and the earlier days through the decay constant, whereas SPEI only considers water surplus or deficit in the period regardless of the conditions the days before. For a 7-day period, for example, if there is no precipitation during the period, it may be regarded as a drought period according to SPEI; however, if there is a heavy precipitation right before the period, the 7-day period probably remains wet and is unlikely to experience droughts. Therefore, SPEI might be inappropriate to monitor droughts with submonthly scale. Such a drawback of SPEI indeed has been pointed out in previous studies (Lu et al. 2014).

Also note that there are some existing extreme weather indicators such as maximum consecutive 5-day precipitation (RX5day) and maximum number of consecutive days with rainfall rate $<1 \mathrm{~mm}$ (CDD) that are useful and simple for monitoring short-term dry/wet conditions (Zhong et al. 2019). However, these indicators may not be robust to quantitatively determine drought conditions because the evolution and severity of drought does not solely rely on precipitation (Otkin et al. 2013, 2014; Ford and Labosier 2017). More importantly, these

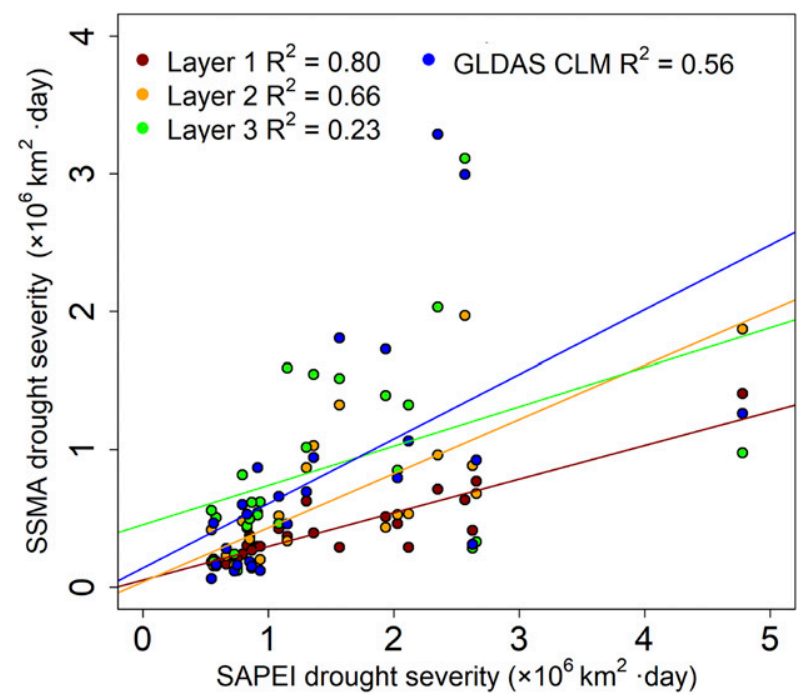

FIG. 13. Correlations between the drought severities of SAPEI and soil moisture simulated by VIC and obtained from GLDAS CLM for the Pearl River basin.

extreme weather indicators do not allow for comparison of drought severity through space and time due to their fixed spatial scale (e.g., regional average). For example, there are two regions with the same CDD for a specific period, with one before that period experiencing heavy rainfall and the other having relative light rainfall. Since CDD does not consider precipitation before that period, it is difficult to compare the drought severities over these two regions. In this regard, SAPEI can fill the gap of the extreme weather indicators and provides a more effective way for assessing drought severity.

\section{b. Application}

Short-term droughts are generally driven by extreme weather anomalies such as high temperatures, low humidity, and strong winds within a short period that cause a significant increase in atmospheric demand, and these anomalies could work together leading to soil moisture decline (Otkin et al. 2018). Previous studies state that short-term droughts occur more frequently in southern regions than in other parts of China (Wang et al. 2016). South China is a humid region where evapotranspiration is mainly controlled by energy supply because soil moisture is usually sufficient. The evaporation demand could increase significantly during a short period when strong, transient meteorological changes occur, which creates a favorable condition for short-term droughts. Due to sufficient soil moisture, vegetation over south China is usually rich and plants tend to suck much water from soil when extreme weather anomalies occur, causing evapotranspiration increase and soil moisture decline and the resultant short-term droughts. Therefore, 
TABLE 2. Short-term drought events during 1961-2015 in the Pearl River basin. DEA_P is referred to as the percentage between the affected and total areas of the basin.

\begin{tabular}{|c|c|c|c|c|c|c|}
\hline Rank & Period & DED (day) & DEI & $\operatorname{DES}\left(\times 10^{5} \mathrm{~km}^{2}\right.$ day $)$ & DEA $\left(\times 10^{4} \mathrm{~km}^{2}\right)$ & DEA_P (\%) \\
\hline 1 & 6-27 Aug 1964 & 22 & 0.87 & 47.81 & 25.00 & 55.1 \\
\hline 2 & 11-29 Sep 1980 & 19 & 0.93 & 26.28 & 14.88 & 32.8 \\
\hline 3 & 1-17 Aug 2007 & 17 & 0.72 & 25.67 & 21.03 & 46.4 \\
\hline 4 & 14 May-10 Jun 2008 & 28 & 0.83 & 25.13 & 10.86 & 23.9 \\
\hline 5 & 3-19 Aug 1983 & 17 & 0.95 & 21.16 & 13.07 & 28.8 \\
\hline 6 & 14-29 Aug 1982 & 16 & 0.7 & 20.29 & 18.22 & 40.2 \\
\hline 7 & 21 Aug-15 Sep 2009 & 26 & 0.55 & 15.67 & 10.87 & 24.0 \\
\hline 8 & 13 Jul-6 Aug 1982 & 25 & 1.05 & 13.02 & 4.95 & 10.9 \\
\hline 9 & 9 Jun-23 Jun 1999 & 15 & 1.29 & 11.50 & 5.95 & 13.1 \\
\hline 10 & 26 Aug-14 Sep 1969 & 20 & 0.44 & 10.82 & 12.27 & 27.0 \\
\hline 11 & 29 May-16 Jun 1986 & 19 & 0.57 & 9.36 & 8.67 & 19.1 \\
\hline 12 & 4-21 Apr 1967 & 18 & 0.61 & 9.13 & 8.38 & 18.5 \\
\hline 13 & 24 May-12 Jun 2013 & 20 & 0.53 & 8.66 & 8.17 & 18.0 \\
\hline 14 & 26 Aug-14 Sep 1978 & 20 & 0.53 & 8.49 & 8.01 & 17.7 \\
\hline 15 & 23 Jul-8 Aug 1961 & 17 & 0.43 & 8.30 & 11.39 & 25.1 \\
\hline 16 & 12 Jun-7 Jul 2000 & 26 & 0.63 & 7.94 & 4.88 & 10.8 \\
\hline 17 & 16 Jun-1 Jul 2014 & 16 & 0.95 & 7.52 & 4.96 & 10.9 \\
\hline 18 & 10-28 Aug 1979 & 19 & 0.77 & 7.27 & 4.99 & 11.0 \\
\hline 19 & 18 Jul-3 Aug 1996 & 17 & 0.27 & 6.64 & 14.29 & 31.5 \\
\hline 20 & 5-20 Jun 1993 & 16 & 0.59 & 5.84 & 6.15 & 13.6 \\
\hline 21 & 15-29 Jun 1962 & 15 & 0.74 & 5.62 & 5.07 & 11.2 \\
\hline
\end{tabular}

short-term droughts are likely to occur in humid regions with dense vegetation (Wang et al. 2016; Otkin et al. 2018).

Here, we chose the Pearl River basin located in humid south China with rich vegetation as a case study ( $\mathrm{Wu}$ et al. 2017b). We characterized historical short-term droughts within the basin using the new drought index. More precisely, the short-term droughts across the basin during the growing season (April-September) from 1961 to 2015 are identified based on SAPEI and the three-dimensional clustering algorithm, after which the drought duration, severity, intensity, and affected area are monitored. Given that short-term drought generally persists for several weeks (Otkin et al. 2016, 2018), only the events lasting for 2-4 weeks are considered.

The historical short-term droughts in the basin are not recorded or reported in detail, and direct verification of the events is impossible. Instead, VIC-based and GLDAS soil moisture are used for validation since soil moisture is sensitive to drought conditions. The standardized anomalies of soil moisture during 1961-2015 are obtained at each grid for comparison. Using the three-dimensional clustering algorithm and the SAPEI time series, the short-term droughts are discerned and the drought severities are computed accordingly. The corresponding drought events are also extracted based on the time series of the standardized anomalies of soil moisture; each cluster of the standardized anomalies of soil moisture has the same spatiotemporal dimension with the drought event identified by SAPEI to ensure they have the same duration and affected area. And the corresponding drought severities based on the clusters of the standardized anomalies of soil moisture are calculated. Figure 13 compares the drought severities revealed by SAPEI and soil moisture (VIC-based and GLDAS). The severity of the standardized anomalies of VIC-based soil moisture in the top soil layer and that of SAPEI are significantly correlated with the coefficient correlation square up to $0.80(p<0.01)$, while relatively low correlations are detected for the standardized anomalies of soil moisture in the second and third soil layers, indicating that soil moisture in the top layer is more sensitive to short-term drought events. In addition, the severity of SAPEI is well correlated with GLDAS soil moisture $(p<0.01)$.

A total of 21 drought events lasting for 2-4 weeks are identified across the basin over the period of record. Only the droughts having affected areas accounting for at least $10 \%$ of the study region are considered and their characteristics (DED, DEI, DES, and DEA) are shown in Table 2. Note that each of the top five drought events has affected more than $25 \%$ of the basin. The most severe event persisted for 22 days from 6 to 27 August 1964 , with affected area up to $25 \times 10^{4} \mathrm{~km}^{2}$ accounting for approximately half of the basin. Events with the same duration could have quite different affected areas and severities, for example, the third and fifteenth drought events. By extension, similar severity may not be necessarily followed by similar duration or affected area. Generally, events having longer durations have 

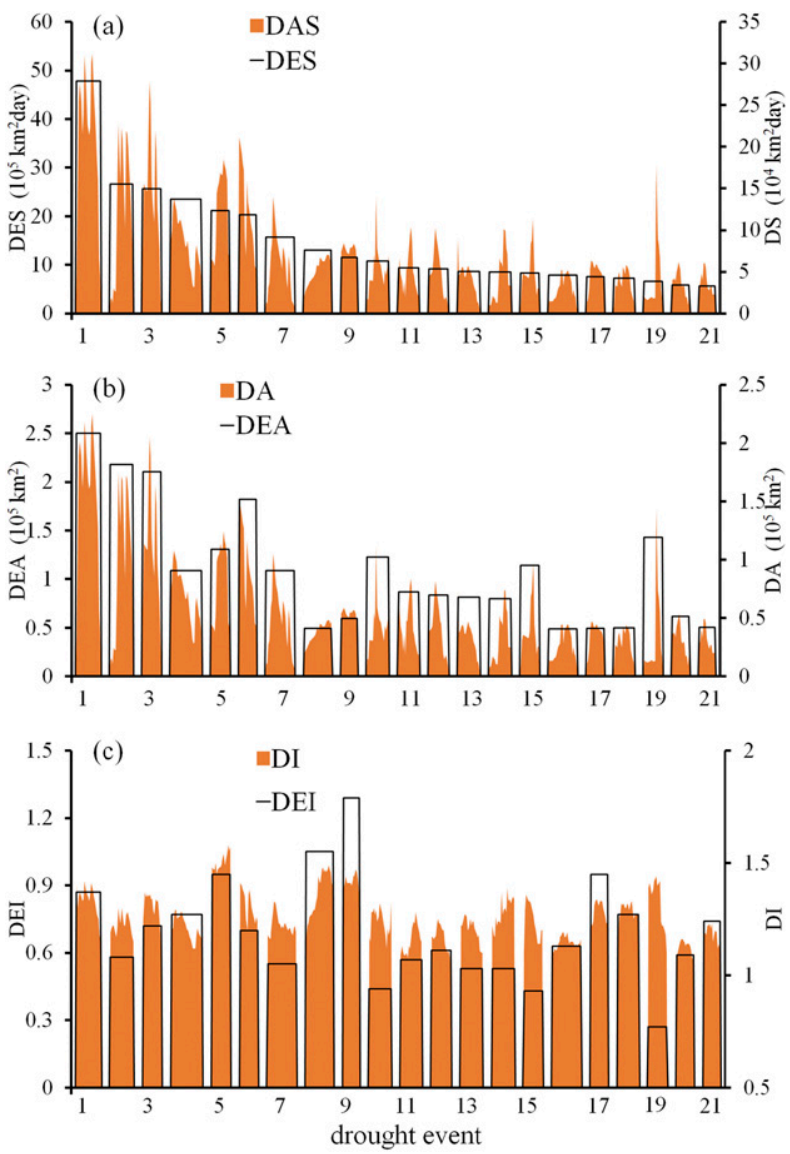

FIG. 14. Evolutions of drought events across the Pearl River basin during 1961-2015. The number on the $x$ axis represents the rank of the event as listed in Table 2.

higher severity and larger affected areas. An exception is that the sixth drought event only lasted about 2 weeks but affected more than $40 \%$ of the basin with relatively high severity. Figure 14 illustrates the temporal changes in drought characteristics for both the whole lifetime (DES, DEA, and DEI) and each time step (DS, DA, and DI). Obviously, although drought events did not last long, some of them have multiple peaks for the severity, affected area, and intensity. Such multipeak features are adverse for drought warning and forecasting because forecasters may mistake temporary decreases in drought severity and affected areas as actual drought relief.

To explore how severe historical droughts evolved at the daily scale, the spatiotemporal evolutions of the top two drought events (Table 2) are picked out for detailed analysis, as depicted in Fig. 15. The most severe drought nearly affected the whole central region of the basin. An obvious north to south track path was found for these events. This drought appeared in the mid-northern part of the basin on 6 August 1964. It gradually extended to most of the central part when the drought condition in
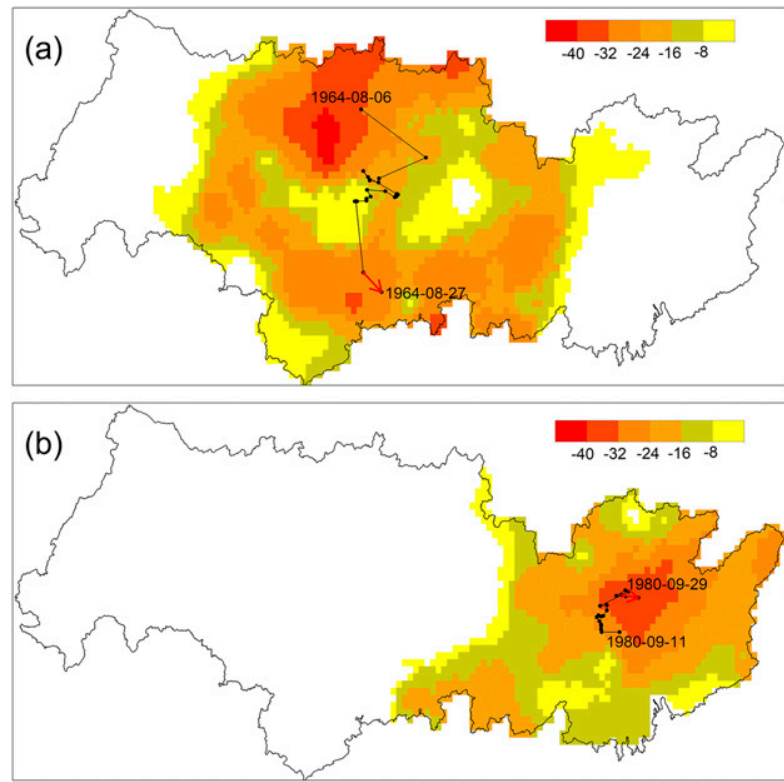

FIG. 15. Spatial changing patterns of the most and second-most severe short-term drought events in the Pearl River basin. (a) The most severe drought event. (b) The second-most severe drought event. The black line indicates the drought evolution track, the black dots indicate the daily drought centers, and the red arrows indicate the terminal point

the mid-northern part became more serious in the following several days, and the drought centers gradually moved south. After then, it faded out and approximately disappeared in the central south of the basin on 27 August. The second severe drought event started in the central part of the basin on 11 September 1980, gradually moved north, and wandered in central region for several days. Finally, the drought finally shrank in the middle north part and ended on 29 September 1980. The most severe region was found in the eastern central region of the basin.

\section{Conclusions}

Drought is a multiscalar phenomenon that can last from a few weeks to years. Correspondingly, a drought index should be able to monitor drought at different time scales in order to reflect different types of droughts. The most commonly used indices employ the yearly or monthly time scale; for short-term droughts, however, there are few indices capable of capturing them. In this study, we developed a new daily scale drought index termed as SAPEI that consider both precipitation and evapotranspiration. Our results reveal that the monthly changes in droughts revealed by SAPEI, SPEI, scPDSI, and soil moisture are fairly consistent. However, the weekly changes monitored by SAPEI and SPEI are 
quite different and the latter one fails to capture drought evolution. At daily scale, the drought conditions based on SAPEI is in accord with soil moisture change demonstrating the capability of SAPEI for tracking shortterm droughts. For the short-term droughts over the Pearl River basin during 1961-2015, many of them have multiple peaks in terms of severity, affected area, and intensity, and some are characterized by high intensity, large affected area, and rapid evolution. The proposed index is potentially an effective way for diagnosing the drought initiation, development, and decay situation, which could be conducive for decision-makers and stakeholders to make early and timely warnings of drought disasters.

Acknowledgments. We appreciate the China Meteorological Administration and the National Inventory of the Forest Ministry of China. The research was funded by the China Postdoctoral Science Foundation (2019M662919), the Visiting Researcher Fund Program of State Key Laboratory of Water Resources and Hydropower Engineering Science (Wuhan University, 2019SWG03) the Fundamental Research Funds for the Central Universities (2019JQ06), and the National Natural Science Foundation of China (51879107, 51709117).

\section{REFERENCES}

Abramowitz, M., and I. A. Stegun, Eds., 1965: Handbook of Mathematical Functions: With Formulas, Graphs, and Mathematical Tables. Courier Corporation, 1046 pp.

Allen, R.G., L.S. Pereira, D. Raes, and M. Smith, 1998: Crop evapotranspiration: Guidelines for computing crop water requirements. FAO Irrigation and Drainage Paper 56, 300 pp., https://www.fao.org/docrep/X0490E/X0490E00.htm.

Andreadis, K. M., E. A. Clark, A. W. Wood, A. F. Hamlet, and D. P. Lettenmaier, 2005: Twentieth-century drought in the conterminous United States. J. Hydrometeor., 6, 985-1001, https://doi.org/10.1175/JHM450.1.

Bi, H., J. Ma, W. Zheng, and J. Zeng, 2016: Comparison of soil moisture in GLDAS model simulations and in situ observations over the Tibetan Plateau. J. Geophys. Res. Atmos., 121, 2658-2678, https://doi.org/10.1002/2015JD024131.

Chen, D., G. Gao, C. Y. Xu, J. Guo, and G. Ren, 2005: Comparison of the Thornthwaite method and pan data with the standard Penman-Monteith estimates of reference evapotranspiration in China. Climate Res., 28, 123-132, https://doi.org/10.3354/cr028123.

Chen, H., and J. Sun, 2015: Changes in drought characteristics over China using the standardized precipitation evapotranspiration index. J. Climate, 28, 5430-5447, https://doi.org/10.1175/JCLID-14-00707.1.

Chen, Y., K. Yang, J. Qin, L. Zhao, and W. Tang, 2013: Evaluation of AMSR-E retrievals and GLDAS simulations against observations of a soil moisture network on the central Tibetan Plateau. J. Geophys. Res. Atmos., 118, 4466-4475, https:// doi.org/10.1002/JGRD.50301.

Christian, J. I., J. B. Basara, J. A. Otkin, E. D. Hunt, R. A. Wakefield, and P. Flanagan, 2019: A methodology for flash drought identification: Application of flash drought frequency across the United States. J. Hydrometeor., 20, 833-846, https:// doi.org/10.1175/JHM-D-18-0198.1.

Cook, B. I., J. E. Smerdon, R. Seager, and S. Coats, 2014: Global warming and 21st century drying. Climate Dyn., 43, 2607-2627, https://doi.org/10.1007/s00382-014-2075-y.

Dai, A., 2013: Increasing drought under global warming in observations and models. Nat. Climate Change, 3, 52-58, https:// doi.org/10.1038/nclimate1633.

Doughty, C. E., and Coauthors, 2015: Drought impact on forest carbon dynamics and fluxes in Amazonia. Nature, 519, 78-82, https://doi.org/10.1038/nature14213.

Feng, X., B. Fu, S. Piao, S. Wang, P. Ciais, and Z. Zeng, 2016: Revegetation in China's Loess Plateau is approaching sustainable water resource limits. Nat. Climate Change, 6, 1019-1022, https://doi.org/10.1038/nclimate3092.

Ford, T. W., and S. M. Quiring, 2013: Influence of MODIS-derived dynamic vegetation on VIC-simulated soil moisture in Oklahoma. J. Hydrometeor., 14, 1910-1921, https://doi.org/10.1175/JHM-D13-037.1.

— ated with the onset of flash drought in the eastern United States. Agric. For. Meteor., 247, 414-423, https://doi.org/ 10.1016/j.agrformet.2017.08.031.

, D. B. McRoberts, and S. M. Quiring, 2015: On the utility of in situ soil moisture observations for flash drought early warning in Oklahoma, USA. Geophys. Res. Lett., 42, 97909798, https://doi.org/10.1002/2015GL066600.

Gao, W., Z. Wang, and G. Huang, 2019: Spatiotemporal variability of actual evapotranspiration and the dominant climatic factors in the Pearl River Basin, China. Atmosphere, 10, 340, https:// doi.org/10.3390/atmos10060340.

Guttman, N. B., 1998: Comparing the palmer drought index and the standardized precipitation index. J. Amer. Water Resour. Assoc., 34, 113-121, https://doi.org/10.1111/j.1752-1688.1998.tb05964.x.

Hamlet, A. F., P. W. Mote, M. P. Clark, and D. P. Lettenmaier, 2007: Twentieth-century trends in runoff, evapotranspiration, and soil moisture in the western United States. J. Climate, 20, 1468-1486, https://doi.org/10.1175/JCLI4051.1.

Hao, Z., X. Yuan, Y. Xia, F. Hao, and V. P. Singh, 2017: An overview of drought monitoring and prediction systems at regional and global scales. Bull. Amer. Meteor. Soc., 98, 18791896, https://doi.org/10.1175/BAMS-D-15-00149.1.

Heggen, R. J., 2001: Normalized antecedent precipitation index. J. Hydrol. Eng., 6, 377-381, https://doi.org/10.1061/(ASCE) 1084-0699(2001)6:5(377).

Heim, R. R., Jr., 2002: A review of twentieth-century drought indices used in the United States. Bull. Amer. Meteor. Soc., 83, 1149-1166, https://doi.org/10.1175/1520-0477-83.8.1149.

Herrera-Estrada, J. E., Y. Satoh, and J. Sheffield, 2017: Spatiotemporal dynamics of global drought. Geophys. Res. Lett., 44, 2254-2263, https://doi.org/10.1002/2016GL071768.

Hoerling, M., J. Eischeid, A. Kumar, R. Leung, A. Mariotti, and K. Mo, 2014: Causes and predictability of the 2012 Great Plains drought. Bull. Amer. Meteor. Soc., 95, 269-282, https:// doi.org/10.1175/BAMS-D-13-00055.1.

Jiao, W., C. Tian, Q. Chang, K. A. Novick, and L. Wang, 2019: A new multi-sensor integrated index for drought monitoring. Agric. For. Meteor., 268, 74-85, https://doi.org/10.1016/ j.agrformet.2019.01.008.

Kam, J., J. Sheffield, X. Yuan, and E. F. Wood, 2014: Did a skillful prediction of sea surface temperatures help or hinder forecasting of the 2012 Midwestern US drought? 
Environ. Res. Lett., 9, 034005, https://doi.org/10.1088/17489326/9/3/034005.

Li, B., H. Beaudoing, and M. Rodell, 2018: GLDAS Catchment Land Surface Model L4 daily $0.25 \times 0.25$ degree V2.0 (GLDAS_CLSM025_D) at GES DISC.GES DISC, accessed 6 August 2019, https://doi.org/10.5067/LYHA9088MFWQ.

Li, J., Z. Wang, X. Wu, S. Guo, and X. Chen, 2020a: Flash droughts in the Pearl River Basin, China: Observed characteristics and future changes. Sci. Total Environ., 707, 136074, https://oi.org/ 10.1016/j.scitotenv.2019.136074.

,$- \ldots$, and C. Lai, 2020b: Severe drought events inducing large decrease of net primary productivity in mainland China during 1982-2015. Sci. Total Environ., 703, 135541, https://doi.org/ 10.1016/j.scitotenv.2019.135541.

Liang, X., D. P. Lettenmaier, E. F. Wood, and S. J. Burges, 1994: A simple hydrologically based model of land surface water and energy fluxes for general circulation models. J. Geophys. Res., 99, 14 415-14 428, https://doi.org/10.1029/94JD00483.

_ , E. F. Wood, and D. P. Lettenmaier, 1996: Surface soil moisture parameterization of the VIC-2L model: Evaluation and modification. Global Planet. Change, 13, 195-206, https:// doi.org/10.1016/0921-8181(95)00046-1.

Liu, Y., Y. Zhu, L. Ren, and V. P. Singh, 2017: A multiscalar palmer drought severity index. Geophys. Res. Lett., 44, 6850-6858, https://doi.org/10.1002/2017GL073871.

Lloyd-Hughes, B., 2012: A spatio-temporal structure-based approach to drought characterization. Int. J. Climatol., 32, 406-418, https:// doi.org/10.1002/joc.2280.

Lohmann, D., E. Raschke, B. Nijssen, and D. P. Lettenmaier, 1998: Regional scale hydrology: I. Formulation of the VIC-2L model coupled to a routing model. Hydrol. Sci. J., 43, 131-141, https:// doi.org/10.1080/02626669809492107.

Long, D., Y. Shen, A. Sun, Y. Hong, L. Longuevergne, and Y. Yang, 2014: Drought and flood monitoring for a large Karst Plateau in southwest China using extended grace data. Remote Sens. Environ., 155, 145-160, https://doi.org/10.1016/ j.rse.2014.08.006.

Lu, E., 2009: Determining the start, duration, and strength of flood and drought with daily precipitation: Rationale. Geophys. Res. Lett., 36, L12707, https://doi.org/10.1029/2009GL038817.

— W. Wai, Z. Jiang, Q. Zhang, C. Zhang, R. W. Higgins, and M. S. Halpert, 2014: The day-to-day monitoring of the 2011 severe drought in China. Climate Dyn., 43, 1-9, https://doi.org/ 10.1007/s00382-013-1987-2.

Maneta, M. P., M. O. Torres, W. W. Wallender, S. Vosti, R. Howitt, and L. Rodrigues, 2009: A spatially distributed hydroeconomic model to assess the effects of drought on land use, farm profits, and agricultural employment. Water Resour. Res., 45, 179-204, https://doi.org/10.1029/2008WR007534.

McKee, T., N. Doesken, and J. Kleist, 1993: The relationship of drought frequency and duration to time scales. Preprints, Eighth Conf. on Applied Climatology, Anaheim, CA, Amer. Meteor. Soc., 179-184.

Miguez-Macho, G., H. Li, and Y. Fan, 2008: Simulated water table and soil moisture climatology over North America. Bull. Amer. Meteor. Soc., 89, 663-672, https://doi.org/10.1175/ BAMS-89-5-663.

Mishra, A. K., and V. P. Singh, 2010: A review of drought concepts. J. Hydrol., 391, 202-216, https://doi.org/10.1016/ j.jhydrol.2010.07.012.

Mizukami, N., O. Rakovec, A. J. Newman, M. P. Clark, A. W. Wood, H. V. Gupta, and R. Kumar, 2019: On the choice of calibration metrics for "high-flow" estimation using hydrologic models.
Hydrol. Earth Syst. Sci., 23, 2601-2614, https://doi.org/10.5194/ hess-23-2601-2019.

Mo, K. C., and D. P. Lettenmaier, 2015: Heat wave flash droughts in decline. Geophys. Res. Lett., 42, 2823-2829, https://doi.org/ 10.1002/2015GL064018.

— , and — 2016: Precipitation deficit flash droughts over the United States. J. Hydrometeor., 17, 1169-1184, https://doi.org/ 10.1175/JHM-D-15-0158.1.

Nijssen, B., R. Schnur, and D. P. Lettenmaier, 2001: Global retrospective estimation of soil moisture using the variable infiltration capacity land surface model, 1980-93. J. Climate, 14, 1790-1808, https://doi.org/10.1175/1520-0442(2001)014<1790: GREOSM $>2.0 . \mathrm{CO} ; 2$.

Niu, J., and J. Chen, 2016: A wavelet perspective on variabilities of hydrological processes in conjunction with geomorphic analysis over the Pearl River basin in South China. J. Hydrol., 542, 392-409, https://doi.org/10.1016/ j.jhydrol.2016.09.017.

- — - and L. Sun, 2015: Exploration of drought evolution using numerical simulations over the Xijiang (West River) basin in South China. J. Hydrol., 526, 68-77, https://doi.org/ 10.1016/j.jhydrol.2014.11.029.

Osborn, T., J. Barichivich, I. Harris, G. van der Schrier, and P. D. Jones, 2017: Monitoring global drought using the selfcalibrating Palmer drought severity index [in "State of the Climate in 2016"]. Bull. Amer. Meteor. Soc., 98 (8) S32-S33, https://doi.org/10.1175/2017BAMSStateoftheClimate.1.

Otkin, J. A., M. C. Anderson, C. Hain, I. E. Mladenova, J. B. Basara, and M. Svoboda, 2013: Examining rapid onset drought development using the thermal infrared-based evaporative stress index. J. Hydrometeor., 14, 1057-1074, https://doi.org/ 10.1175/JHM-D-12-0144.1.

,,--- , and M. Svoboda, 2014: Examining the relationship between drought development and rapid changes in the evaporative stress index. J. Hydrometeor., 15, 938-956, https:// doi.org/10.1175/JHM-D-13-0110.1.

—, M. Shafer, M. Svoboda, B. Wardlow, M. C. Anderson, and C. Hain, 2015: Facilitating the use of drought early warning information through interactions with agricultural stakeholders. Bull. Amer. Meteor. Soc., 96, 1073-1078, https:// doi.org/10.1175/BAMS-D-14-00219.1.

, and Coauthors, 2016: Assessing the evolution of soil moisture and vegetation conditions during the 2012 United States flash drought. Agric. For. Meteor., 218-219, 230-242, https://doi.org/ 10.1016/j.agrformet.2015.12.065.

M. Svoboda, E. D. Hunt, T. W. Ford, M. C. Anderson, C. Hain, and J. B. Basara, 2018: Flash droughts: A review and assessment of the challenges imposed by rapid-onset droughts in the United States. Bull. Amer. Meteor. Soc., 99, 911-919, https://doi.org/10.1175/BAMS-D-17-0149.1.

PaiMazumder, D., and J. M. Done, 2016: Potential predictability sources of the 2012 U.S. drought in observations and a regional model ensemble. J. Geophys. Res. Atmos., 121, 12 581-12 592, https://doi.org/10.1002/2016JD025322.

Palmer, W. C., 1965: Meteorological drought. U.S. Weather Bureau Research Paper 45, 58 pp., http://www.ncdc.noaa.gov/ temp-and-precip/drought/docs/palmer.pdf.

Panu, U. S., and T. C. Sharma, 2002: Challenges in drought research: Some perspectives and future directions. Hydrol. Sci. J., 47, S19-S30, https://doi.org/10.1080/02626660209493019.

Portela, M. M., J. F. dos Santos, A. T. Silva, J. B. Benitez, C. Frank, and J. M. Reichert, 2015: Drought analysis in southern Paraguay, Brazil and northern Argentina: Regionalization, 
occurrence rate and rainfall thresholds. Hydrol. Res., 46, 792810, https://doi.org/10.2166/nh.2014.074.

Quiring, S. M., and T. N. Papakryiakou, 2003: An evaluation of agricultural drought indices for the Canadian prairies. Agric. For. Meteor., 118, 49-62, https://doi.org/10.1016/ S0168-1923(03)00072-8.

Rhee, J., and J. Im, 2017: Meteorological drought forecasting for ungauged areas based on machine learning: Using long-range climate forecast and remote sensing data. Agric. For. Meteor., 237-238, 105-122, https://doi.org/10.1016/j.agrformet.2017.02.011.

Rhee, J. Y., J. H. Im, and G. J. Carbone, 2010: Monitoring agricultural drought for arid and humid regions using multi-sensor remote sensing data. Remote Sens. Environ., 114, 2875-2887, https://doi.org/10.1016/j.rse.2010.07.005.

Rodell, M., P. R. Houser, U. E. A. Jambor, J. Gottschalck, K. Mitchell, and C. J. Meng, 2004: The Global Land Data Assimilation System. Bull. Amer. Meteor. Soc., 85, 381-394, https://doi.org/10.1175/BAMS-85-3-381.

Sheffield, J., K. M. Andreadis, E. F. Wood, and D. P. Lettenmaier, 2009: Global and continental drought in the second half of the twentieth century: Severity-area-duration analysis and temporal variability of large-scale events. J. Climate, 22, 19621981, https://doi.org/10.1175/2008JCLI2722.1.

Stagge, J. H., L. M. Tallaksen, L. Gudmundsson, and A. F. Van Loon, 2015: Candidate distributions for climatological drought indices (SPI and SPEI). Int. J. Climatol., 35, 4027-4040, https:// doi.org/10.1002/joc.4267.

Thornthwaite, C., 1948: An approach toward a rational classification of climate. Geogr. Rev., 38, 55-94, https://doi.org/10.2307/ 210739.

Trenberth, K. E., A. Dai, G. van der Schrier, and P. D. Jones, 2014: Global warming and changes in drought. Nat. Climate Change, 4, 17-22, https://doi.org/10.1038/nclimate2067.

Vicente-Serrano, S. M., and S. Beguería, 2016: Comment on 'Candidate distributions for climatological drought indices (SPI and SPEI)' by James H. Stagge et al. Int. J. Climatol., 36, 2120-2131, https://doi.org/10.1002/joc.4474.

,$- \ldots$, and J. I. López-Moreno, 2010a: A multiscalar drought index sensitive to global warming: The standardized precipitation evapotranspiration index. J. Climate, 23, 1696-1718, https://doi.org/10.1175/2009JCLI2909.1.

,,,--- M. Angulo, and A. E. Kenawy, 2010b: A new global 0.5 gridded dataset (1901-2006) of a multiscalar drought index: Comparison with current drought index datasets based on the Palmer Drought severity index. J. Hydrometeor., 11, 1033-1043, https://doi.org/10.1175/2010JHM1224.1.

— , D. G. Miralles, F. Domínguez-Castro, and C. Azorin-Molina, 2018: Global assessment of the Standardized Evapotranspiration Deficit Index (SEDI) for drought analysis and monitoring. J. Climate, 31, 5371-5393, https://doi.org/10.1175/JCLI-D17-0775.1.

Wang, L., C. Wen, and Z. Wen, 2015: Drought in southwest China: A review. Atmos. Oceanic Sci. Lett., 8, 339-344, https://doi.org/10.3878/AOSL20150043.

, X. Yuan, Z. Xie, P. Wu, and Y. Li, 2016: Increasing flash droughts over China during the recent global warming hiatus. Sci. Rep., 6, 30571, https://doi.org/10.1038/srep30571.
Wang, Z., R. Zhong, C. Lai, Z. Zeng, Y. Lian, and X. Bai, 2018: Climate change enhances the severity and variability of drought in the Pearl River Basin in South China in the 21st century. Agric. For. Meteor., 249, 149-162, https://doi.org/ 10.1016/j.agrformet.2017.12.077.

Wells, N., S. Goddard, and M. J. Hayes, 2004: A self-calibrating Palmer drought severity index. J. Climate, 17, 2335-2351, https:// doi.org/10.1175/1520-0442(2004)017<2335:ASPDSI>2.0.CO;2.

Wu, X., Z. Wang, X. Zhou, C. Lai, W. Lin, and X. Chen, 2016 Observed changes in precipitation extremes across 11 basins in China during 1961-2013. Int. J. Climatol., 36, 2866-2885, https://doi.org/10.1002/joc.4524.

,,,,---- and X. Chen, 2017a: Trends in temperature extremes over nine integrated agricultural regions in China 1961-2011. Theor. Appl. Climatol., 129, 1279-1294, https:// doi.org/10.1007/s00704-016-1848-0.

$\longrightarrow,-$ S. Guo, W. Liao, Z. Zeng, and X. Chen, 2017b: Scenariobased projections of future urban inundation within a coupled hydrodynamic model framework: A case study in Dongguan City. China. J. Hydrol., 547, 428-442, https://doi.org/10.1016/ j.jhydrol.2017.02.020.

- S. Guo, J. Yin, G. Yang, and Y. Zhong, 2018: On the eventbased extreme precipitation across China: Time distribution patterns, trends, and return levels. J. Hydrol., 562, 305-317, https://doi.org/10.1016/j.jhydrol.2018.05.028.

Xia, Y., J. Sheffield, M. B. Ek, J. Dong, and N. Chaney, 2014: Evaluation of multi-model simulated soil moisture in NLDAS-2. J. Hydrol., 512, 107-125, https://doi.org/10.1016/j.jhydrol.2014.02.027.

Xu, K., D. Yang, H. Yang, Z. Li, and Y. Qin, 2015: Spatio-temporal variation of drought in China during 1961-2012: A climatic perspective. J. Hydrol., 526, 253-264, https://doi.org/10.1016/ j.jhydrol.2014.09.047.

Yan, D., S. E. Werners, F. Ludwig, and H. Q. Huang, 2015 Hydrological response to climate change: The Pearl River, China under different RCP scenarios. J. Hydrol., 4, 228-245, https://doi.org/10.1016/j.ejrh.2015.06.006.

Yu, H., Q. Zhang, C.-Y. Xu, J. Du, and P. Sun, 2019: Modified Palmer Drought severity index: Model improvement and application. Environ. Int., 130, 104951, https://doi.org/10.1016/ j.envint.2019.104951.

Zhang, J., W. C. Wang, and J. Wei, 2008: Assessing landatmosphere coupling using soil moisture from the Global Land Data Assimilation System and observational precipitation. J. Geophys. Res., 113, D17119, https://doi.org/10.1029/ 2008JD009807.

Zhang, Y., Q. You, C. Chen, and X. Li, 2017: Flash droughts in a typical humid and subtropical basin: A case study in the Gan River Basin, China. J. Hydrol., 551, 162-176, https://doi.org/ 10.1016/j.jhydrol.2017.05.044.

Zhong, R., X. Chen, C. Lai, Z. Wang, Y. Lian, H. Yu, and X. Wu, 2019: Drought monitoring utility of satellite-based precipitation products across mainland China. J. Hydrol., 568, 343-359, https://doi.org/10.1016/j.jhydrol.2018.10.072.

Zhou, Y., S. Guo, C. Xu, H. Chen, and J. Guo, 2016: Probabilistic prediction in ungauged basins (PUB) based on regional parameter estimation and Bayesian model averaging. Hydrol. Res., 47, 1087-1103, https://doi.org/10.2166/nh.2016.058. 